\title{
Experimental data from the Benchmark SuperCritical Wing wind tunnel test on an oscillating turntable
}

\author{
Jennifer Heeg ${ }^{1}$ and David J. Piatak ${ }^{1}$ \\ NASA Langley Research Center, Hampton, Virginia, 23681
}

\begin{abstract}
The Benchmark SuperCritical Wing (BSCW) wind tunnel model served as a semi-blind testcase for the 2012 AIAA Aeroelastic Prediction Workshop (AePW). The BSCW was chosen as a testcase due to its geometric simplicity and flow physics complexity. The data sets examined include unforced system information and forced pitching oscillations. The aerodynamic challenges presented by this AePW testcase include a strong shock that was observed to be unsteady for even the unforced system cases, shock-induced separation and trailing edge separation. The current paper quantifies these characteristics at the AePW test condition and at a suggested benchmarking test condition. General characteristics of the model's behavior are examined for the entire available data set.
\end{abstract}

\section{Nomenclature}
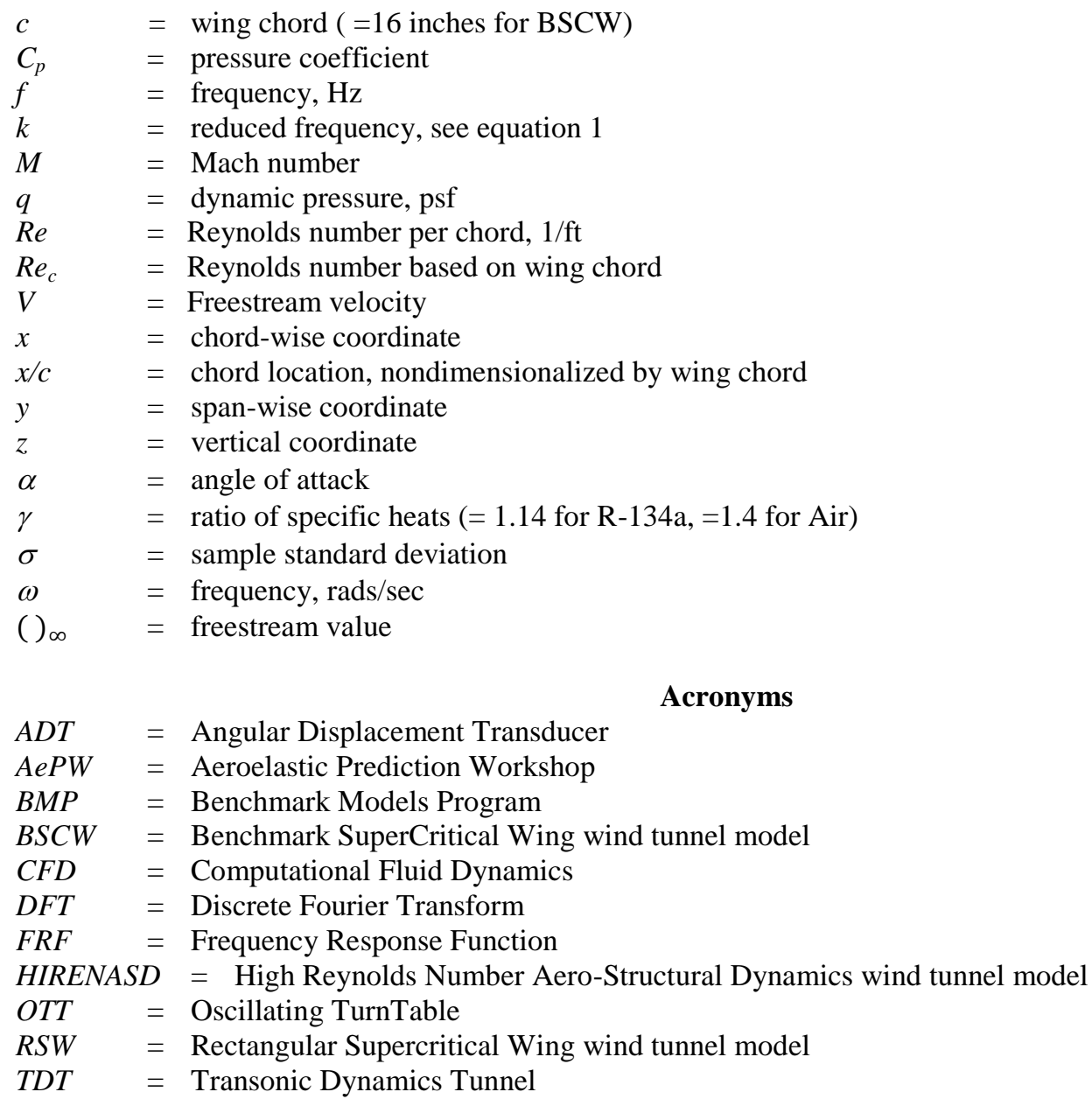

\footnotetext{
${ }^{1}$ Research engineer, Aeroelasticity Branch, Mail Stop 340, AIAA Senior Member.
}

1

American Institute of Aeronautics and Astronautics 


\section{Introduction}

$\mathrm{F}$ LOW field features can make the seemingly simplest geometry difficult to analyze. The Benchmark Supercritical Wing (BSCW) is an excellent example where this is true. The BSCW was chosen as a testcase for the recent AIAA Aeroelastic Prediction Workshop (AePW) ${ }^{1,2,3,4}$ for this very reason- geometric simplicity combined with flow physics that would challenge the participating analysts. Although the analysts were not told to use any particular level of flow physics modeling, it was thought that most would use Unsteady Reynolds' Averaged Navier Stokes (URANS) codes. Results from teams analyzing the BSCW for the AePW can be found in references 5,6 and 7.

The long-range goals of AePW team are to assess the state of the art in aeroelastic computational tools and to determine future directions for code development and aeroelastic validation experiments. The workshop approach was to use existing experimental data sets where forced oscillations were applied to wind tunnel models and detailed unsteady data was acquired. The BSCW configuration satisfied these requirements and was exceptional in several other ways. The latest test of the BSCW was fairly recent; the detailed data files and the people responsible for conducting the test were both available. Secondly, little had been published ${ }^{8}$ regarding this data, making it a semiblind computational testcase.

This paper presents additional details of the data at the test conditions analyzed for the AePW, (Mach 0.85, $\alpha=$ $5^{\circ}$, dynamic pressure of $200 \mathrm{psf}, \mathrm{Re}_{\mathrm{c}}=4.49 \times 10^{6}$ ). The data sets discussed will include the unforced system data and forced oscillation data sets. The test points analyzed for the AePW include forced oscillations at $1 \mathrm{and} 10 \mathrm{~Hz}$ only. The data presented will not be limited to these excitation frequencies, but they will be used to exemplify points where possible.

The AePW test condition produced separated flow at both the foot of the shock and at the airfoil trailing edge. The qualitative characteristics of the system change when the flow becomes separated. Evidence of this separated flow is shown and the resulting behaviors identified and quantified. A major change for the separated flow case is that the shock movement changes direction relative to angle of attack changes. This is important because the forced oscillations for BSCW model were pitching motions. That is, the wing was rotated sinusoidally through an angle of attack range. This type of forced oscillation was not chosen arbitrarily; flutter mechanisms (i.e. unstable aeroelastic systems) frequently involve a wing torsion mode which in a simplified form is an airfoil pitching motion.

Data sets from additional test conditions are briefly shown and summarized in this paper. Because the AePW test condition is so challenging, a recommendation for a less challenging test condition for computational benchmarking, (Mach 0.70, $\alpha_{0}=3^{\circ}$ ), is made and example data shown. This suggested test case contains an oscillatory shock, but data analysis indicates that the behavior is not driven by separated flow. Although the AePW test condition is challenging, it is likely not the most challenging one available. Additional test cases are briefly discussed where the flow is alternatingly attached and separated as the wing is oscillated in pitch, (Mach $0.80, \alpha_{0}=$ $\left.5^{\circ}\right)$, (Mach $\left.0.85, \alpha_{0}=1^{\circ}\right)$.

Data reduction methods are often applied without explicitly listing the consequences of those methods. Unforced system data is often represented by the mean value of that data set. In this paper, we explore the unforced system data in detail. Dynamic characteristics are present in that data. Fourier analysis has been applied to the data to generate power spectral density (PSD) functions and frequency response functions (FRFs). These methods are linear and contain the underlying assumption that both the input and output are responding at the same frequency. Reducing the data in this way, produces a simplified method of capturing some characteristics but simultaneously eliminates other characteristics that may be important to understand and model. In this paper, we present the data analyzed using these tools, but with commentary regarding the consequences.

The objectives of this paper are 1) to present sufficient detail for computational studies to be conducted with better knowledge of the experimental data; 2) to develop an understanding of the flow physics and 3) to provide connection to the aeroelastic characteristics. 


\section{Background: Separated flow}

In 1989, Denis Mabey wrote ${ }^{9}$ that "no significant progress has been made to solve the general problem of the prediction of the response of wings to the small-scale, random pressure fluctuations characteristic of buffet excitation. The prediction of these small-scale pressure fluctuations probably requires accurate mathematical models of the small-scale turbulence that may not become available for many years." This was a major motivation behind his detailed study of experimental data bases where separated flow had been observed. Mabey investigated buffeting criteria using experimental data bases from 11 wings of varying design, focusing principally on how the design variables impacted buffet onset and severity. Specific to the transonic test conditions of the BSCW, he noted that shock-induced separation was prone to onset at a substantially lower lift coefficient (and by extension, a lower angle of attack) than the other types of buffet. Among the design variables investigated, Mabey reported that for a thicker airfoil, the shocks are strengthened and separation occurs at lower Mach number and angle of attack. He also pointed out that any airfoil change that leads to an increase in the adverse pressure gradient between the shock and the trailing edge will lead to separation occurring at a lower angle of attack.

Shock induced separation in turbulent boundary layers at transonic conditions are described by Pearcey. ${ }^{10}$ Pearcey observed the same behavior that is being reported for the BSCW, "The development and effects of separation for increasing incidence at constant Mach number ... include a reversal of the movement of the upper surface shock from rearwards to forwards." This characteristic is also shown in data presented by Hurley et al. ${ }^{11}$ for a supercritical airfoil designated DSMA 523, and by Bartels and Edwards ${ }^{12}$ for a supercritical SC(2)-0714 airfoil.

The influence of the Mach number on the pressure change across the static shock, where shock-induced trailing edge separation (SITES) occurs, is investigated by Cunningham and Spragle. ${ }^{13}$ They point out that for a constant Mach number, the pressure coefficient at the foot of the shock for separation onset, regardless of angle of attack, occurs at the sonic value of $\mathrm{Cp}$. They also observe that the pressure change across the static shock is constant with respect to angle of attack, for a given Mach number, and show a shifting of the shock location towards the leading edge with increasing angle of attack for the ONERA M_6 at Mach 0.92, $\operatorname{Re}_{\mathrm{c}} 11.7 \times 10^{6}$. Cunningham and Spragle state that increasing the Reynolds number increases the energy in the boundary layer, so the flow requires a higher shock pressure change to induce separation. Thus, a higher Reynolds number case will exhibit a larger change in the pressure coefficient across the shock.

When separated flow is present, is there specific frequency content in the aerodynamic forcing function? This is of particular interest when considering aeroelastic systems that can be destabilized with unfortunate coincidence of forcing frequencies with structural dynamic frequencies. For the NACA 0012 airfoil tested by McDevitt and Okuno, ${ }^{14}$ there was clear evidence in the pressure data that there was cyclical aerodynamic behavior, as shown in the reproduced plots below, Figure 1. They showed that the clarity of frequency was dependent on the Reynolds number- a Reynolds numbers $\left(\operatorname{Re}_{\mathrm{c}}\right)$ of 7 million and above produced sinusoidal pressure responses and enabled them to determine the frequency content of the separated flow field. For Reynolds numbers below 6 million, however, the pressure data contained a larger random component. Results from reference 14 are shown in Table 1, where the frequency representation has been changed to correspond to reduced frequency, as defined by equation 1 .

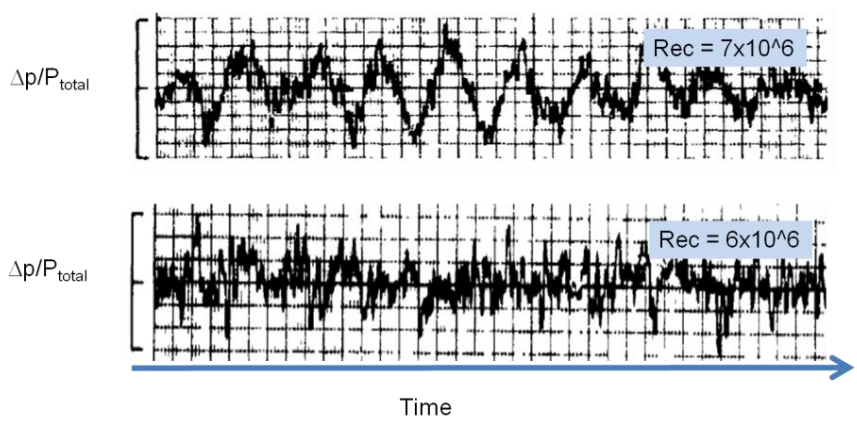

Figure 1. Upper surface pressure coefficients at $80 \%$ chord, well aft of the upper surface shock $(\mathrm{x} / \mathrm{c}=0.45)$ from wind tunnel testing of a NACA 0012 airfoil, Mach $0.775, \alpha 4^{\circ}$, (reference 14) 
Table 1. Shock-oscillation reduced frequency at $\operatorname{Re}_{\mathrm{c}}=7$ million, NACA 0012 airfoil, (reference 14)

\begin{tabular}{ccc} 
Mach & $\alpha^{\circ}$ & $\mathrm{k}$ \\
\hline \hline 0.72 & 6 & 0.275 \\
0.75 & 4 & 0.235 \\
0.77 & 4 & 0.22 \\
0.8 & 4 & 0.19 \\
$k=\frac{\omega c}{2 V_{\infty}}$ &
\end{tabular}

Assessment of local separation induced by the shock, and occurring at the foot of the shock, is performed in the current paper using a modification of the guideline developed by Pearcey. ${ }^{10}$ The isentropic flow relationship given in equation 2 can be employed to calculate the local Mach number ahead of the shock, $\mathbf{M}_{\text {local }}$. This quantity is calculated using the pressure coefficient value at the leading edge of the shock, $\mathrm{C}_{\mathrm{p}, \text { local }}$, the freestream Mach number, $\mathrm{M}_{\infty}$, and the ratio of specific heats for the test medium, $\gamma$. Pearcey's guideline was that a shock was of sufficient strength to induce separation if the local Mach number exceeded 1.27. In the current study, a Mach number value of 1.3 was used as the criterion.

$$
M_{\text {local }}=\sqrt{2 /(\gamma-1) \frac{1+\frac{\gamma-1}{2} M_{\infty}^{2}}{\left(C_{p, \text { local }} \gamma M_{\infty}^{2} / 2+1\right)^{\frac{\gamma-1}{\gamma}}}-1}
$$

Separation at the trailing edge was assessed by examining the pressure coefficients near the trailing edge on the upper surface. Two criteria have been applied in the current paper: a positive value of pressure coefficient at the trailing edge and the change in trailing edge pressure coefficient due to angle of attack. The second assessment follows Charpin ${ }^{15}$ who examined the slopes of the pressure coefficient with respect to angle of attack to determine the combination of Mach number and angle of attack for separation onset.

Assessing separation on the lower surface, in the region of the cusp, is based principally on the shape of the pressure distribution in that region. An increase in the dynamic response is also considered a signal that separation has occurred, or the boundary layer has become greatly thicker.

\section{Wind tunnel model \& facility}

The BSCW was tested in the NASA Transonic Dynamics Tunnel (TDT) ${ }^{16}$ as part of the Benchmark Models Program (BMP) ${ }^{17,18,19}$ on a Pitch and Plunge Apparatus (PAPA) and later as a testbed for hardware checkout of the Oscillating TurnTable (OTT) system. ${ }^{8}$ The model is shown mounted in the wind tunnel during testing on the OTT, Figure 2. The data obtained during the OTT testing is the data primarily examined in this paper.

\section{A.BSCW hardware}

The BSCW airfoil is a supercritical SC(2)-0414, shown in Figure 4. The airfoil designation indicates that is was part of the $2^{\text {nd }}$ generation of designed supercritical airfoils, with a design normal force coefficient of 0.4 and a $14 \%$ thickness to chord ratio. A planform of the model is shown in Figure 3 and geometric parameters are listed in Table 2. The model has a rectangular planform with a wing tip cap shaped as a tip of revolution. The model pitch axis was located at the $30 \%$ chord. Boundary layer transition was fixed for the OTT testing, using \#30 grit applied at $7.5 \%$ chord to the upper and lower wing surfaces. 


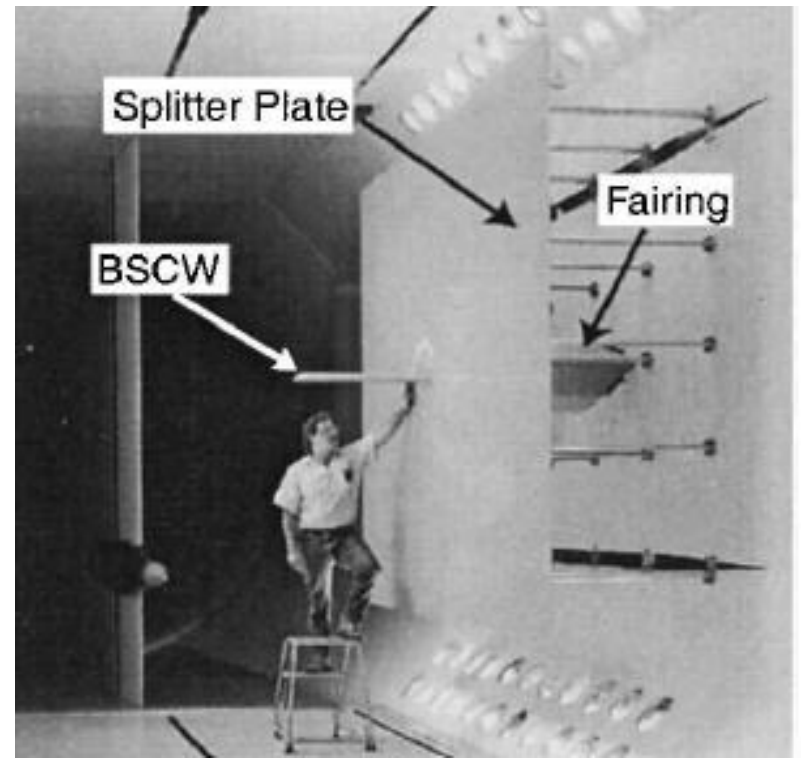

Figure 2. BSCW mounted in TDT.

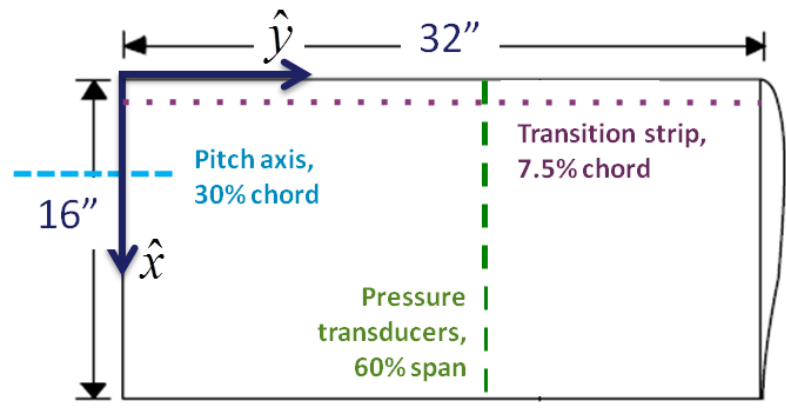

Figure 3. BSCW planform view.

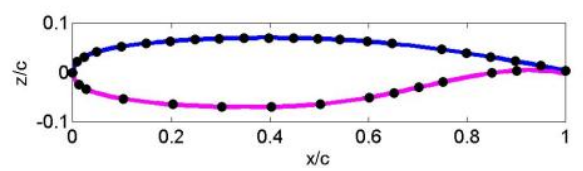

Figure 4. BSCW airfoil shape, SC(2)-0414, and transducer locations

The principal measurements for this data set were unsteady pressures. The model originally included 80 surface pressure orifices; 40 located at $60 \%$ span and 40 located at $95 \%$ span. For the OTT test, only the $60 \%$ span station was populated with pressure transducers; the chord-wise locations are shown in Figure 4 and listed in Table 3. Insitu unsteady pressure transducers $( \pm 5 \mathrm{psi})$ with a repeatability and hysteresis of $0.1 \%$ were utilized. Details of the transducer geometry, given in reference 17 for the testing during the BMP, are also valid for this test data set, although the pressure tube manifolding was different. The pressure transducers were calibrated in place prior to testing using a reference pressure of \pm 0.0025 psi. The calibrations were checked before and after each test run. Reference pressure tubes were vented to an area of zero flow in the tunnel plenum. Thus, each differential pressure transducer was referenced to free stream stagnation pressure.

Other instrumentation included angular displacement transducers (ADTs) mounted at the aft end of the OTT and at the splitter plate to measure the angle of attack at these two locations. There were also microphones located on the tunnels surfaces and accelerometers located near the four corners of the model, on the splitter plate and at various locations on the OTT.

\section{B.Transonic Dynamics Tunnel}

The TDT is a closed circuit, continuous flow wind tunnel that operates between near vacuum and atmospheric pressures. The TDT can employ either air or heavy gas as a test medium. The empty-tunnel Mach number capabilities are extended up to Mach 1.2 using slotted wind tunnel walls and flow recapture flaps. The test section is 16 -ft square with cropped corners. For this test, the wind tunnel wall slots were open and the reported data was acquired in heavy gas, R-134a. The ratio of specific heats for gaseous R-134a is different from air, approximately 1.116 , mildly dependent on temperature. ${ }^{20}$ The more dominant influence on the ratio of specific heats is the purity of the test medium. For this test, the R-134a test medium purity varied between 88 and $99 \%$, with the remaining percentage of the gas being air introduced by tunnel leakage. 


\section{C.Oscillating TurnTable}

The OTT was used as the model oscillation system for the BSCW testing. The OTT was designed to oscillate large semispan models in pitch with the intent of capturing forced oscillation pressure information for unsteady aerodynamic code validation. The BSCW data sets being examined in this paper were obtained during check-out testing of the OTT hardware. The OTT hardware and the initial test results for the BSCW are given in reference 8 . The pitching inertia of the BSCW model at its maximum test condition was calculated to be less than $2 \%$ of the design limit of the OTT hardware. The goal of testing this model was to push the limits of the hardware in terms of frequency capabilities, testing up to $30 \mathrm{~Hz}$, and to characterize the unsteady pressure behavior under the extreme operating conditions of the OTT.

\section{D.Splitter plate}

A large splitter plate was utilized in this test. It was 12 feet in length and 10 feet in height, suspended from the tunnel wall by 40 inch long struts. The chord-wise center of the model was located 7 feet from the splitter plate leading edge. An aerodynamic fairing ran from the splitter plate to the wall. The wing root of the model was attached to a pan that rotated within a circular opening in the splitter plate. The splitter plate was instrumented with some surface pressure measurements, but the locations of these transducers were not measured and differ from those shown in references 17 and 21.

A calibration test of this splitter plate was conducted by Schuster. ${ }^{21}$ In that work, examination of splitter plate surface pressure measurements led to the conclusion that there was the potential for shocks to form at the splitter plate leading edge for Mach numbers exceeding 0.8. Additionally, boundary layer rake data showed that by Mach 0.85 , it was likely that upstream shocks were resulting in a thickening of the boundary layer on the splitter plate at the model mounting location. At Mach 0.85 , the boundary layer thickness was measured as approximately 4 inches. However, it was also demonstrated that the pressure gradient on the splitter plate was flat up to Mach 0.95. Although the recommendation was to limit this splitter plate's use for aerodynamic measurements to a Mach number no greater than Mach 0.8, the AePW proceeded to use the Mach 0.85 test condition as the test case for the AePW.

The impacts of the splitter plate and potential viscous effects at this test condition have not been assessed. A detailed assessment was performed regarding the Rectangular Supercritical Wing (RSW) model and its splitter plate. $^{3}$ In that instance, however, the splitter plate was substantially undersized and was demonstrated to be engulfed in the wind tunnel wall boundary layer. The impacts of the BSCW splitter plate are thought to be mild by comparison for the reasons discussed in the preceding paragraphs.

\section{E.Test conditions \& data sets}

The test cases selected for the AePW were a small subset of the available data sets from the wind tunnel testing of the BSCW on the OTT. The cases specific to the AePW are listed in Table 4. The matrix full matrix of test conditions for which data was obtained in R-134a is given in Table 5. At each of these test conditions, the mean angle of attack was varied and separate data sets acquired for $\alpha_{0}=\left[-1^{\circ}, 0^{\circ}, 1^{\circ}, 3^{\circ}\right.$ and $\left.5^{\circ}\right]$. At each of these angles of attack, several types of data were acquired. Unforced system data was acquired for at least 5 seconds. The second type of data set acquired was a sine dwell, where the OTT maintained one oscillation frequency of specified amplitude for five to fifteen seconds, depending on the frequency. For $0^{\circ}$ and $5^{\circ}$ angles of attack, sine dwell data was acquired at frequencies of 1 to $15 \mathrm{~Hz}$, obtained at intervals of $1 \mathrm{~Hz}$ were acquired, along with $20 \mathrm{and} 30 \mathrm{~Hz}$. The amplitudes were generally 1 degree, but were reduced for the $20 \mathrm{~Hz}$ cases $\left(0.5^{\circ}\right)$ and $30 \mathrm{~Hz}$ cases $\left(0.2^{\circ}\right)$. There were additional data sets collected at 4 and $5 \mathrm{~Hz}$ with amplitude of $2^{\circ}$. For the other angles of attack, subsets of these frequencies were used. For the third type of data, frequency sweeps were performed, acquiring data in 3 time records covering different frequency ranges: 1.5-10, 11-14.5 and 16-20 Hz.

The data sets were acquired at 1000 samples/sec. The standard length of an unforced system data set was 5 seconds, while the forced oscillation data set lengths were between 5 and 15 seconds. 
Table 2. Reference quantities.

\begin{tabular}{lcc} 
& & BSCW \\
\hline \hline Reference chord & $c_{\text {ref }}$ & 16 in \\
\hline Model span & b & 32 in \\
\hline Area & A & $512 \mathrm{in}^{2}$ \\
\hline Moment & $\mathrm{x}$ & 4.8 in \\
reference & $\mathrm{y}$ & 0 \\
point & $\mathrm{z}$ & 0 \\
\hline
\end{tabular}

$\begin{array}{ll}\text { Transfer } & \\ \text { function } & \text { Pitch } \\ \text { reference } & \text { angle } \\ \text { quantity } & \end{array}$

Table 3. Pressure orifice locations, $x / c$, at $60 \%$ span

\begin{tabular}{|c|c|c|c|}
\hline \multicolumn{2}{|l|}{ Upper } & \multicolumn{2}{|l|}{ Lower } \\
\hline Transducer \# & $\mathrm{x} / \mathrm{c}$ & Transducer \# & $\mathrm{x} / \mathrm{c}$ \\
\hline 1 & 0 & 1 & 0.012 \\
\hline 2 & 0.009 & 2 & 0.027 \\
\hline 3 & 0.023 & 3 & 0.103 \\
\hline 4 & 0.049 & 4 & 0.203 \\
\hline 5 & 0.099 & 5 & 0.303 \\
\hline 6 & 0.149 & 6 & 0.403 \\
\hline 7 & 0.198 & 7 & 0.503 \\
\hline 8 & 0.249 & 8 & 0.602 \\
\hline 9 & 0.298 & 9 & 0.652 \\
\hline 10 & 0.348 & 10 & 0.702 \\
\hline 11 & 0.398 & 11 & 0.752 \\
\hline 12 & 0.448 & 12 & 0.851 \\
\hline 13 & 0.498 & 13 & 0.901 \\
\hline 14 & 0.542 & & \\
\hline 15 & 0.598 & & \\
\hline 16 & 0.648 & & \\
\hline 17 & 0.749 & & \\
\hline 18 & 0.799 & & \\
\hline 19 & 0.849 & & \\
\hline 20 & 0.899 & & \\
\hline 21 & 0.95 & & \\
\hline 22 & 1 & & \\
\hline
\end{tabular}

Table 4. BSCW analysis conditions for AePW

\begin{tabular}{c|c|c|c|c|c} 
Mach & $\begin{array}{c}\text { Mean } \alpha \\
(\mathrm{deg})\end{array}$ & $\begin{array}{c}\text { Pitch Osc. Freq. } \\
(\mathrm{f}, \mathrm{Hz})\end{array}$ & $\begin{array}{c}\text { Pitch Osc. Amp. } \\
(\theta, \mathrm{deg})\end{array}$ & $\begin{array}{c}\text { Reduced Freq. } \\
\omega \mathrm{c} / 2 V_{\infty}\end{array}$ & $\begin{array}{c}R e_{c} \\
* 10^{6}\end{array}$ \\
\hline 0.85 & 5.0 & 0 & 0 & 0 & 4.49 \\
0.85 & 5.0 & 1 & 1.0 & 0.009 & 4.49 \\
0.85 & 5.0 & 10 & 1.0 & 0.090 & 4.49
\end{tabular}

Table 5. BSCW testing conditions and associated blade passage frequencies of the TDT, Test 548

\begin{tabular}{cccc} 
Mach & $\begin{array}{c}\text { Dynamic Pressure } \\
(\mathrm{psf})\end{array}$ & $\begin{array}{c}\text { Motor Speed } \\
(\text { RPM })\end{array}$ & $\begin{array}{c}\text { Blade Passage Frequency } \\
(\mathrm{Hz})\end{array}$ \\
\hline \hline 0.4 & 100 & 108 & 84 \\
0.5 & 100 & 135 & 106 \\
0.5 & 170 & 133 & 104 \\
0.6 & 100 & 159 & 124 \\
0.6 & 170 & 158 & 124 \\
0.7 & 100 & 190 & 149 \\
0.7 & 170 & 184 & 144 \\
0.8 & 100 & 212 & 166 \\
0.8 & 170 & 210 & 164 \\
0.8 & 200 & 212 & 166 \\
0.85 & 200 & 229 & 179 \\
0.87 & 100 & 235 & 184 \\
0.87 & 170 & 235 & 184
\end{tabular}

\section{F. Structural dynamic \& facility aerodynamic modes}

The BSCW model was treated as a rigid wing for the purposes of the AePW. This was considered to be a reasonable approximation, assisted by selecting the forcing frequencies to be separated from the measured structural dynamic frequencies of the system. The modes of the BSCW model, mounted on the OTT supporting strut were measured to be $24.1,27.0$ and $79.9 \mathrm{~Hz}$ for the first spanwise bending, first in-plane bending and first torsion modes, 
respectively. These were the frequencies measured air-off. Note that these frequencies are not related to the plunge and pitch modes discussed in prior BSCW references, as those were associated principally with the PAPA mount system.

A vertical mode of the splitter plate was measured near $15 \mathrm{~Hz}$ air-off and is evident in accelerometers and splitter plate variables of the data set.

Additionally, a facility aerodynamic mode is known to be associated with the blade passage frequency. This frequency varies as the motor rotational speed varies. The motor RPM, converted to seconds and multiplied by the number of fan blades, 47, produces a different frequency for each test condition, specified by combination of Mach number and dynamic pressure. For the BSCW test conditions, these frequencies are listed in Table 5. Note that these frequencies are a direct function of the motor speed. The motor speed associated with a given test condition varies slightly based on other operational parameters.

\section{Unforced system data}

Steady data is often acquired and the statistics, such as mean value, reported for a system sitting in the turbulent freestream of a wind tunnel. The data sets for the BSCW, however, are not well-characterized by these statistics, as they contain dynamic or unsteady characteristics even for the system without any forced motion. This issue is discussed in detail with regard to the RSW configuration in reference 22. Much of that discussion was based on analysis of data for the BSCW configuration and will be revisited with illustrative data sets.

The unforced system is examined here using several representations of the pressure coefficients: time histories, smear plots showing the time history data as a function of chord location, statistics, limits and histograms. Additionally, Fourier analysis is performed to generate power spectral density (PSD) results to examine the frequency content of the pressures and other sensors. Although frequency response functions (FRFs) were generated to examine the pressure response relative to the measured angle of attack, these results are not presented in this paper for the unforced system data.

The unforced system data contains oscillating shocks on both the upper and lower surfaces. At the AePW test condition, the BSCW has shock-separated flow at the foot of the upper surface shock and separated flow at the trailing edge. Dynamic analysis of the pressure data gives indications that the flow is separated throughout the aft region. One question associated with studying separated flows, is whether or not there are distinct aerodynamic modes. Frequencies associated with the separated flow aerodynamics have not been definitively identified for the BSCW, although several frequencies stand out in Fourier analysis of the unforced system data.

The data shown in this section focuses on the AePW test conditions and a second test case that is recommended for computational benchmarking, as detailed in Table 6. This second test case was chosen after a detailed examination of the conditions for incipient separation. The objective in choosing this test case was to have a condition at which the complications associated with separated flow were eliminated, but yet the oscillating shocks were still present in the forced system data. The AePW test case represents a case with more complexity- a separated flow situation. It is envisioned that additional cases would be selected for future studies that includes alternating attached and separated flow, exemplified by the test cases described in the last two columns of Table 6 .

Table 6. Recommended BSCW test cases

\begin{tabular}{rcccccc} 
& Units & $\begin{array}{c}\text { Separated } \\
\text { flow } \\
\text { (AePW) }\end{array}$ & $\begin{array}{c}\text { Attached } \\
\text { flow } \\
\text { (Benchmark) }\end{array}$ & $\begin{array}{c}\text { Likely alternating } \\
\text { attached \& separated } \\
\text { (Future) }\end{array}$ \\
\hline Mach & $M_{\infty}$ & & 0.85 & 0.7 & 0.85 & 0.8 \\
Angle of attack & $\alpha$ & degs & 5 & 3 & 1 & 5 \\
Reynolds number per chord & $\mathrm{Re}$ & $x 10^{6} / \mathrm{ft}$ & 3.36 & 3.42 & 3.36 & 3.49 \\
Reynolds number & $R e_{c}$ & $x 10^{6}$ & 4.48 & 4.56 & 4.48 & 4.65 \\
Dynamic pressure & $\mathrm{q}$ & $\mathrm{psf}$ & 200 & 170 & 200 & 200 \\
Velocity & $V_{\infty}$ & $\mathrm{ft} / \mathrm{sec}$ & 468.8 & 387.3 & 468.8 & 444.3
\end{tabular}




\section{A. Time history representation}

The unsteady pressure data acquired at the AePW test condition is shown as a function in time in Figure 5; the upper and lower surface pressure traces have been plotted separately for ease of viewing and the vertical axis of the plot is shown inverted. This inverted axis convention will be maintained for all data shown in this paper. Each sensor's response is represented by a different colored line of data points that progress with time.

Although the legends have been removed from the plot, the pressures on the upper surface are shown to separate themselves into groups based on the location of the transducers: leading edge, forward of the shock, near the shock and aft of the shock. The leading edge transducer, measuring the pressure near the leading edge suction peak, is shown isolated at the bottom of the upper surface plot, with a pressure coefficient greater than 1 for all time points. Another obvious feature in the plot is the seemingly erratic, large variation, response of the pressure transducer that the shock is crossing during the time history. Response of this pressure transducer located at $\mathrm{x} / \mathrm{c}=0.50$, is shown by the cyan data points between $\mathrm{Cp}$ values of -0.5 and -1.2 . This response will be examined subsequently in more detail. The other sensors fall into two groups: those with very low variation, shown principally underneath the shock-oscillation trace, and those with higher variation, shown between approximately $\mathrm{Cp}=0$ and -0.5 . The former group is ahead of the shock; the latter group is aft of the shock.

The lower surface pressures, Figure 5b, are divided into two groups also. There is also a lower surface shock that is not well-captured in this data due to sensor position relative to that shock. The data points ahead of the shock are shown by the traces with low variation. The data corresponding to transducers aft of the shock are shown by the traces with larger variation.

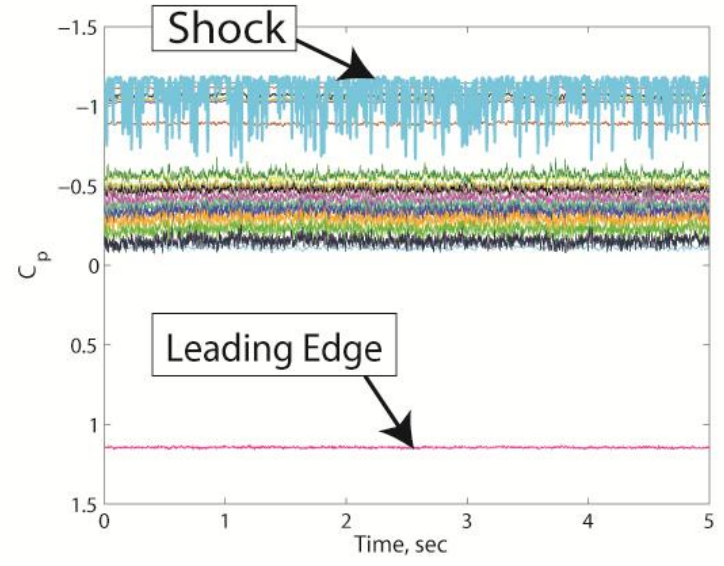

a) Upper surface

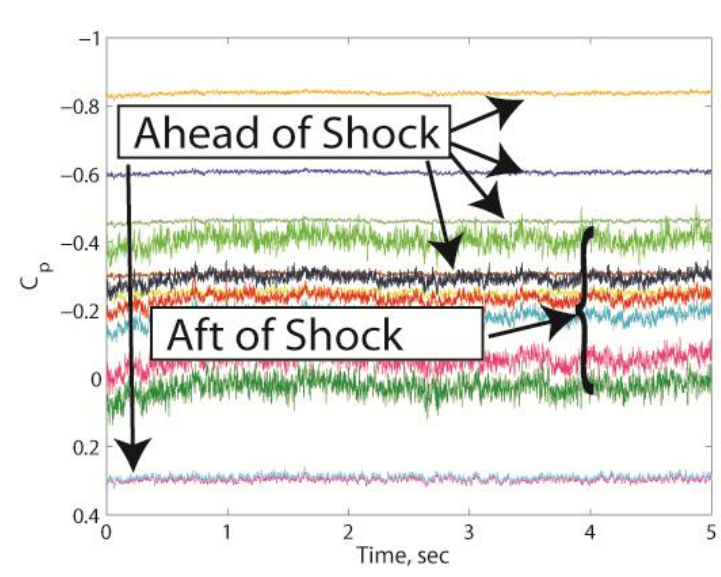

b) Lower surface

Figure 5. Time histories of pressure coefficients, Mach $0.85,5^{\circ}, 200 \mathrm{psf}$, unforced system data

The time history data in the vicinity of the upper surface shock, between $\mathrm{x} / \mathrm{c}=0.4$ and 0.6 , is presented on a finer scale in Figure 6. The time histories are color-matched to the transducer locations shown in the upper subplot.

These time histories should be viewed while looking at the smear plot of the pressure coefficients shown in Figure 7. As the shock moves across the sensor, the pressure value changes from the supersonic plateau (ahead of the shock) to the subsonic and possibly separated region at the foot of the shock. The time history shows pressure floors and ceilings. The resulting time history appears nonlinear for a fixed spatial location when that location is crossed by the moving shock. Analyzed with a histogram, Figure 8a, the results have a highly skewed distribution. 


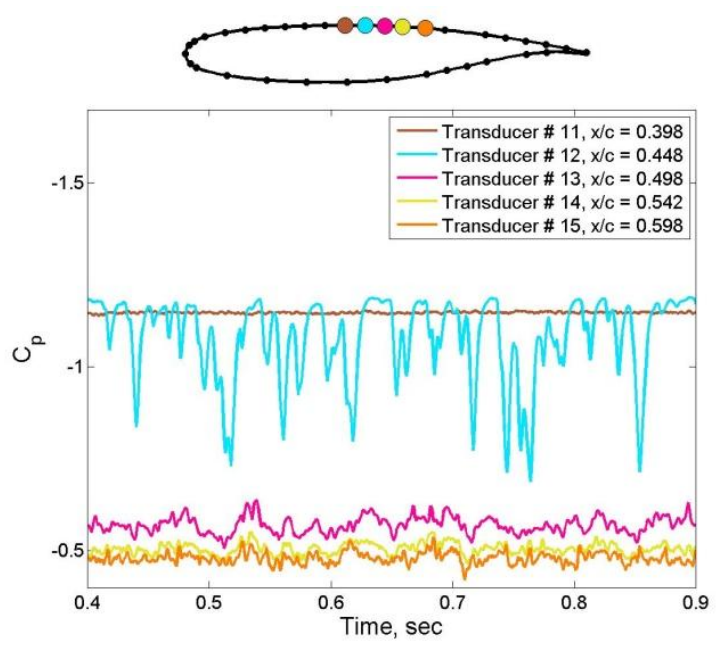

Figure 6. Time histories of pressure coefficients in the vicinity of the shock, Mach $0.85,5^{\circ} \alpha, 200$ psf, unforced system data

The time history data of the pressure coefficients are shown as functions of chord location in Figure 7. Figure 7a shows the entire chord and Figure $7 \mathrm{~b}$ focuses on the points near the upper surface shock. In each of these plots, the smeared time histories appear as grey regions. The figures were generated by plotting the pressure distribution for every point in time. Here, this means that the grey bands are composed of 5000 snapshots of the pressure distribution. Also shown on the plot is the mean value for each of the transducer locations, as well as upper and lower data bounds. White area within the bounds shows positions that the pressure distribution is less likely to assume.

The mean value is only a good representation of a data set if that data set is symmetric. In the case of the transducer that is crossed by the shock, the mean is a poor representation. This is illustrated by examining the data shown in Figure $7 \mathrm{~b}$. The black lines show the pressure distribution taken from 20 sequential time points. The behavior of the shock can be interpreted several ways. The sparseness of pressure measurements in this area means that the true sharpness (verticality) of the shock is difficult to observe. Based on the information in hand, as the shock moves towards the leading edge, it must either shorten or tilt, possibly both. At the aft-most position from the subset of time points, the shock is shown to be almost as tall and vertical as possible and remains within the limits observed in the data set.

Histogram representations the transducers in the vicinity of the shock, Figure 8, indicate that the position and shape represented by this aft-most snapshot is the more likely distribution of the pressure than that shown by the mean values. Specifically, note that the histogram of the data from transducer 12 , at $\mathrm{x} / \mathrm{c}=0.45$, is highly weighted towards the lower value of the pressure coefficient. Recall that the vertical axes on the pressure distributions are inverted.

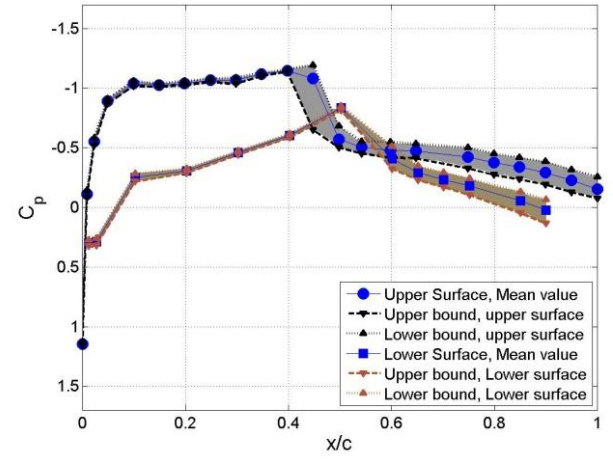

a) Pressure distribution for unforced system data including mean, limits and smeared time histories

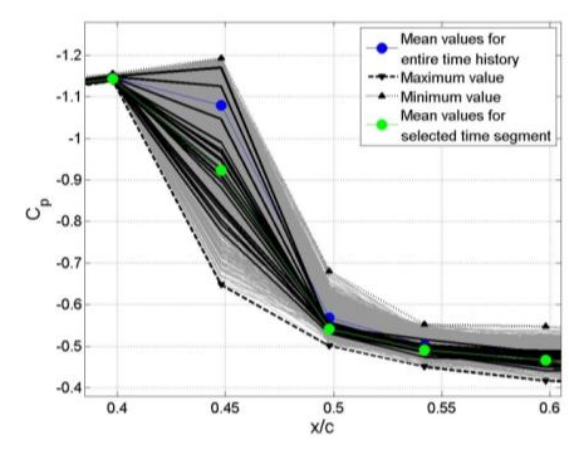

b) Focus on the shock region

Figure 7. Unforced system data for AePW test condition (Mach $0.85,5^{\circ} \alpha, 200 \mathrm{psf}$ ) 


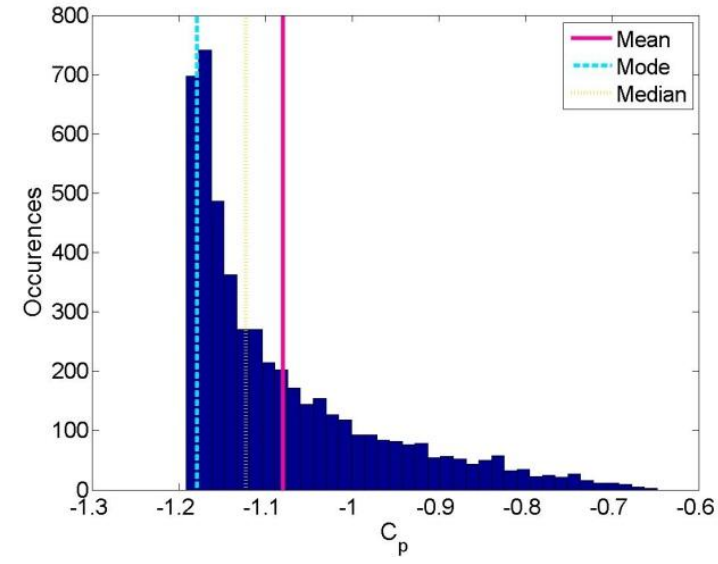

a) Upper surface transducer \#12, $\mathrm{x} / \mathrm{c}=\mathbf{0 . 4 5}$

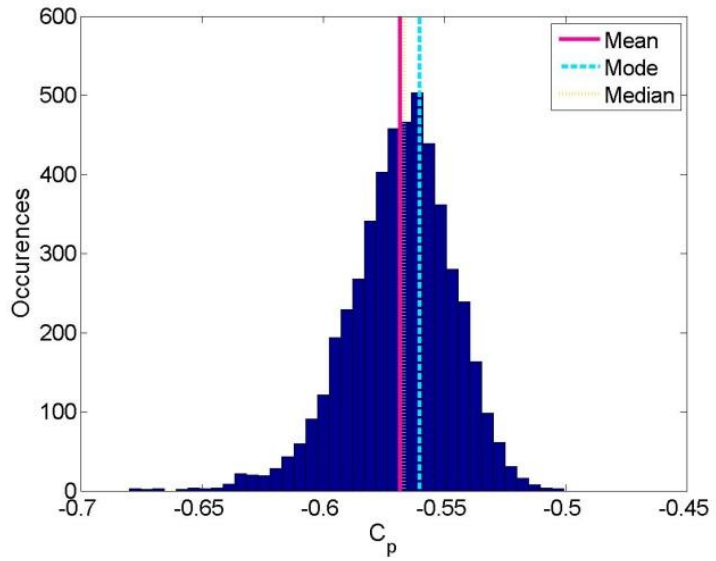

b) Upper surface transducer \#13, $\mathrm{x} / \mathrm{c}=\mathbf{0 . 5 0}$

Figure 8. Histograms of unforced system data for AePW test condition (Mach $0.85,5^{\circ} \alpha, 200 \mathrm{psf}$ )

The nonlinear, ragged nature of the behavior of transducer 12 only indicates shock motion, not separated flow. The increase in the standard deviations in the pressure coefficients aft of the shock, relative to the values for sensors forward of the shock is an indicator of flow separation. As discussed earlier, the time histories show that some sensors have more dynamic content than others. The standard deviation for all sensors is plotted in Figure 9 to quantify this dynamic content, although it has been demonstrated that not all responses have normal distributions. The dynamic content of the data divides the upper surface pressures into the distinct groups discussed earlier: those ahead of the shock, near the shock and aft of the shock. Similarly, the lower surface pressures divide themselves into two groups: those ahead of and aft of the shock. The distribution of standard deviation, obtained from the no oscillatory data, will be shown to closely resemble the magnitude of the FRFs of the forced oscillation systems.

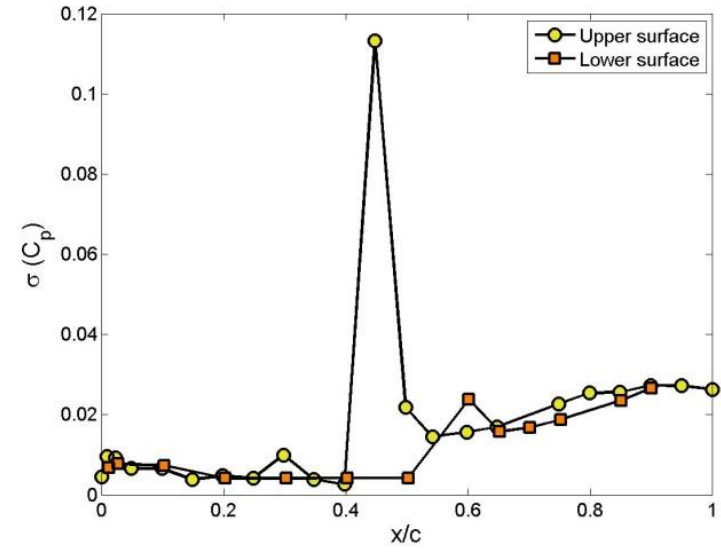

Figure 9. Standard deviation of pressure coefficients, Mach $0.85,5^{\circ} \alpha, 200 \mathrm{psf}$, unforced system data

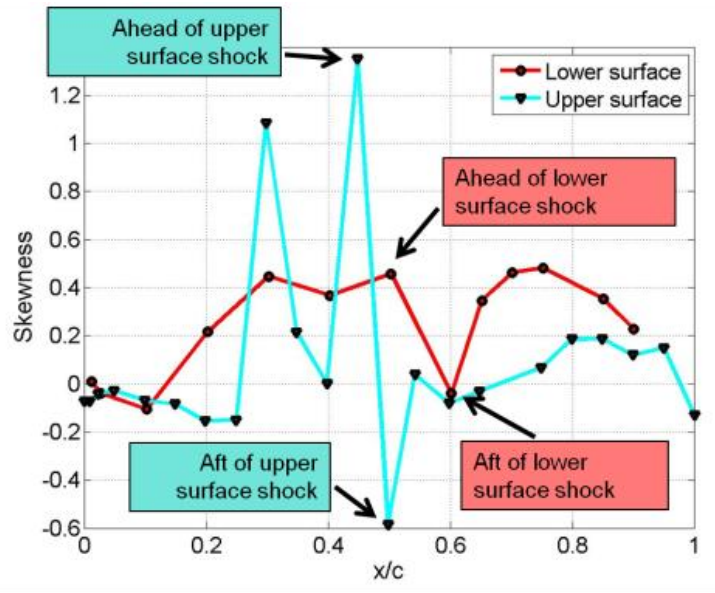

Figure 10. Skewness of pressure transducers indicating position of the upper and lower surface shocks, unforced system data, Mach $0.85, \alpha=5^{\circ}$

The figures above indicate the upper surface shock position to be at 40-50\% chord. The lower surface shock is thought to be located just forward of the $45 \%$ chord. This assessment was based on histograms of the data, and computations of the skewness for each sensor as shown in Figure 10. Left skewness of a histogram of a sensor near the shock means that the sensor generally favors a lower value of pressure coefficient (a larger absolute value). Lower values of the pressure coefficient correspond to the values found on the supersonic pressure plateau, ahead of the shock. The calculated skewness in this case is a positive value. So, a positive skewness value indicates that a given sensor tends to be ahead of the shock. Vice versa, right skewness of a histogram (a negative value) indicates that a sensor generally favors a higher value of pressure coefficient (a smaller absolute value) indicative of the 
values aft of the shock. Interpretations of the skewness at locations away from the shock are not given here, but follow similar logic in terms of favored values.

\section{B.Mean pressure distributions}

The shortcomings of representing these data sets with a mean value have already been discussed. Here, the mean value for all sensors is used for consistency, although for sensors near the shock location the mode is a better representation. Regardless of which statistical first moment is chosen to represent the data, the first moment is a useful tool for examining trends. The data is presented in this format to examine the behavior with changing angle of attack at a constant Mach number. Figure 11 shows the upper surface pressure distributions for three test conditions. Each subplot contains data at each of the five mean angles of attack where data was acquired for this test, $\alpha=\left[-1^{\circ}, 0^{\circ}, 1^{\circ}, 3^{\circ}\right.$ and $\left.5^{\circ}\right]$.

One of the most interesting characteristics of this airfoil is observed by studying this Figure 11. For the low Mach number (Mach 0.70, Figure 11a), as the angle of attack increases, the upper surface shock moves aft. For the high Mach number (Mach 0.85, Figure 11c), as the angle of attack increases, the shock moves forward. At Mach 0.8 , Figure $11 \mathrm{~b}$, the data sets present a mixed picture, as the shock moves aft for angles below $3^{\circ}$ and then migrates back forward as the angle of attack is increased to $5^{\circ}$.

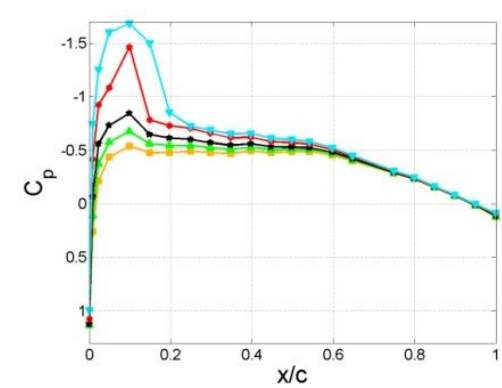

a) Mach 0.7, $170 \mathrm{psf}$

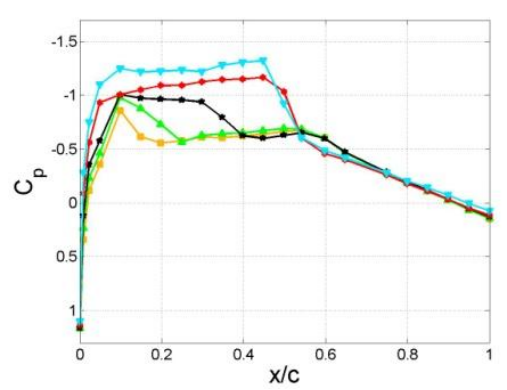

b) Mach 0.8, $200 \mathrm{psf}$

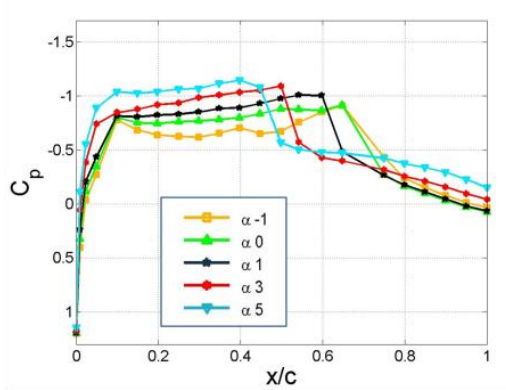

c) Mach 0.85, $200 \mathrm{psf}$

Figure 11 Mean values of upper surface pressure coefficient vs. chord location, unforced system

At Mach 0.7, the shock is difficult to discern at lower angles of attack. The $3^{\circ}$ case shows the shock occurring at a location forward of the shock for the $5^{\circ}$ case, showing that the shock moves aft with increasing angle of attack.

The data at Mach 0.85, Figure 11c, shows the opposite behavior. At $5^{\circ}$, the cyan triangles, the shock is shown near the midchord, between $x / c=0.45$ and 0.5 . For $3^{\circ}$, the shock has moved aft, now located between 0.5 and 0.55 . For $1^{\circ}$, the shock is between $\mathrm{x} / \mathrm{c}=0.6$ and 0.65 . This data clearly shows the shock moving forward with increasing angle of attack. This is a qualitative change from the behavior observed at Mach numbers below Mach 0.8.

To better illustrate the shock position change at a low Mach number, data sets from the PAPA test are shown in Figure 12. The PAPA test data contains more angles of attack, making it easier to follow the progression. At this Mach number, the upper surface shock is evident for the $2.24^{\circ}$ case shown by the black line and symbols. Increasing the angle of attack to $3.15^{\circ}$ moves the upper surface shock aft, as indicated by the green line and symbols. Subsequent increase to $4.16^{\circ}$ (yellow) and $4.89^{\circ}$ (blue) move the upper surface shock still further aft. 


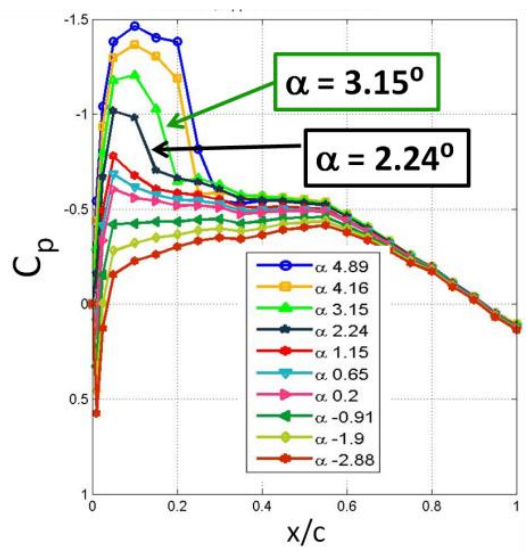

Figure 12 Mean values of upper surface pressure coefficient from PAPA testing of the BSCW, Mach 0.74, 200 psf

The lower surface mean pressure distributions are shown in Figure 13, corresponding to the OTT test conditions shown previously for the upper surface. The trends here are less clear for several reasons. Data at only one negative angle of attack was acquired and the distribution of pressure sensors on the lower surface is sparser. Additionally, the lower surface cusp of the supercritical airfoil in general produces a thickened boundary layer in that region, further complicating the flow field picture. ${ }^{3}$

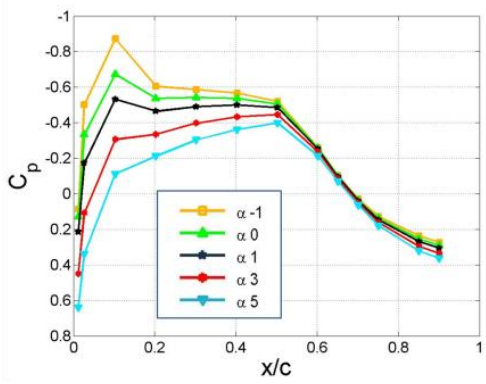

a) Mach 0.7, $170 \mathrm{psf}$

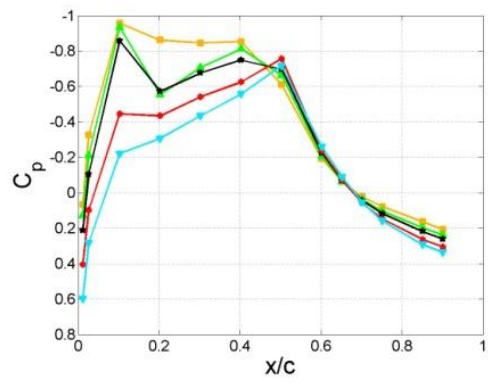

b) Mach 0.8, $200 \mathrm{psf}$

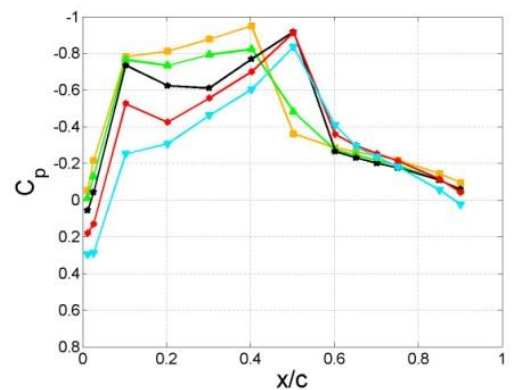

c) Mach 0.85, $200 \mathrm{psf}$

Figure 13 Mean values of lower surface pressure coefficient vs. chord location, unforced system

For the AePW, the purpose in examining this data set was to benchmark computational aeroelastic codes. It is likely important to capture the correct qualitative behavior of the shock motion with respect to angle of attack if the computational method being used is to be extended to aeroelastic analysis.

\section{Aft load distribution}

The mean pressure distributions draw attention to the shock position. However, another trend to notice is the change in the pressure distribution shape aft of the shock. The mean pressure distributions are examined again, this time for a fixed angle of attack, $5^{\circ}$, shown in Figure 14. The low Mach number cases' upper surface pressure distributions all have a downward convex shape near the trailing edge. At Mach 0.8, the distribution is now a flat downward slope. At Mach 0.85 , the shape is more highly convex than at the lower Mach numbers. Consulting the previous plot, Figure 11c, the distribution is shown to be highly dependent on angle of attack. The lower surface distributions have a relatively monotonic slope aft of the lower surface shock for all test conditions. This is in contrast to the supercritical airfoil pressure distributions published by Harris ${ }^{23,24}$ and for the RSW configuration. This is pointed out here because the aft region of the airfoil was not well predicted by any of the computational teams for the AePW. ${ }^{4}$ 


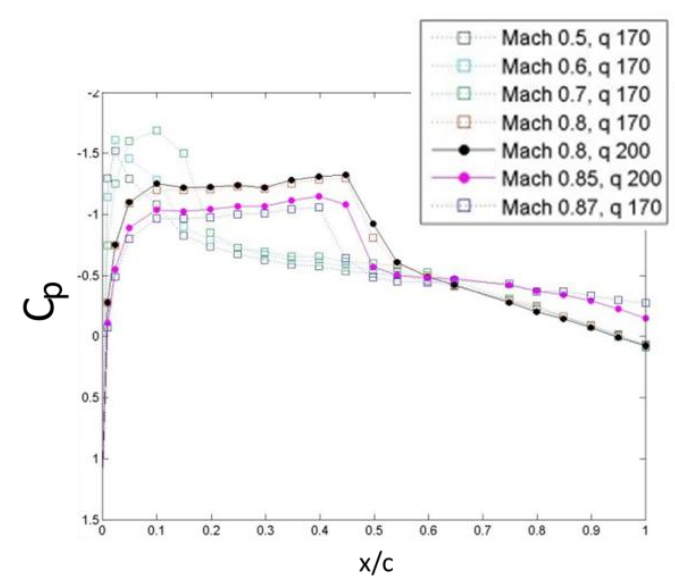

a) Upper surface

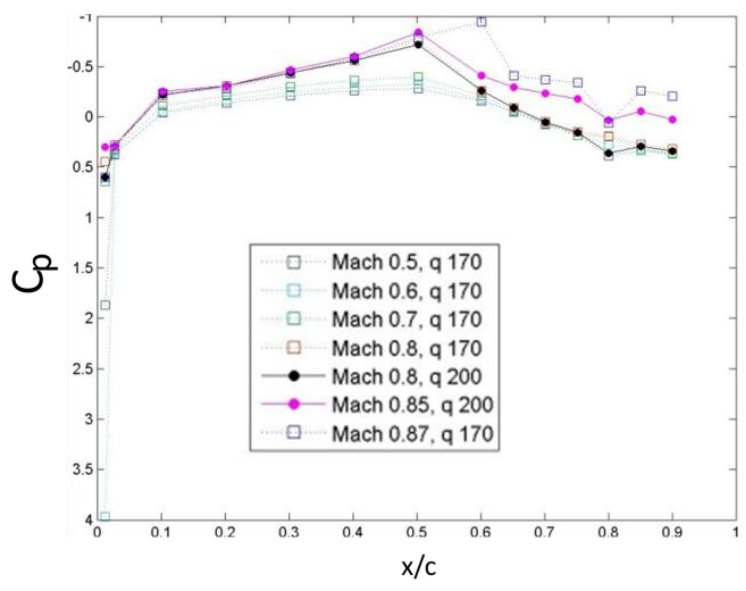

b) Lower surface

Figure 14. Mean pressure distributions, $5^{\circ} \alpha$, unforced system data.

\section{Separation assessment}

Three regions of possible separated flow have been discussed: at the foot of the shock, at the trailing edge and in the lower surface cusp region. Equation 2 was applied to the minimum value of the pressure coefficient for each case of the unforced system. Table 7shows the test conditions that were assessed as containing local shock-separated flow on the upper surface. The orange circles with the black outlines show the test conditions where the time history of the local Mach number spans across the Mach number separation criterion value, 1.3. The numerical values listed in the table show the maximum local Mach number at conditions that are adjacent to those where local separation was assessed to have been present. In several of these cases, using a slightly different test criterion value would have resulted in them being classified as shock-separated.

Table 7. Local shock induced separation conditions

\begin{tabular}{|c|c|c|c|c|c|c|c|c|c|}
\hline \multirow[t]{2}{*}{ Mach } & \multirow{2}{*}{0.6} & \multicolumn{2}{|c|}{0.7} & \multicolumn{3}{|c|}{0.8} & \multirow{2}{*}{0.85} & \multicolumn{2}{|c|}{0.87} \\
\hline & & 100 & 170 & 100 & 170 & 200 & & 100 & 170 \\
\hline-1 & & & & & & & 1.27 & 1.28 & 1.28 \\
\hline 0 & & & & & & & 1.28 & $x$ & 0 \\
\hline 1 & & & & 1.21 & 1.21 & 1.22 & 0 & 0 & 0 \\
\hline 3 & & 1.20 & 1.21 & 1.29 & 0 & 0 & 0 & 0 & 0 \\
\hline \multirow[t]{2}{*}{5} & 1.07 & 1.29 & 0 & 0 & 0 & 0 & 0 & 0 & 0 \\
\hline & \multicolumn{9}{|c|}{$\begin{aligned} & \text { Shock-induced separation } \\
& \text { X } \text { Shock-induced separation onset } \\
& \text { X } \text { Data unavailable } \\
& \text { Number value } \text { Sub-critical, maximum local Mach }\end{aligned}$} \\
\hline
\end{tabular}

Trailing edge separation assessment criteria were discussed earlier. These criteria were applied to all unforced system test conditions and are shown plotted in Figure 15. A negative value of pressure coefficient here indicates that the flow is separated at the trailing edge. Further, a steep change with angle of attack indicates separated flow. By both criteria, at Mach 0.87, all combinations of dynamic pressure and angles of attack have trailing edge separated flow. The Mach 0.85 cases are shown to be separated by both criteria for angles of attack at $3^{\circ}$ and $5^{\circ}$. At the lower angles of attack, the two criteria present a mixed story, perhaps indicating separated flow. For the lower Mach numbers, the angle of attack change criterion indicates that the flow may be separated at the trailing edge at $5^{\circ}$ for the Mach 0.80 cases. 


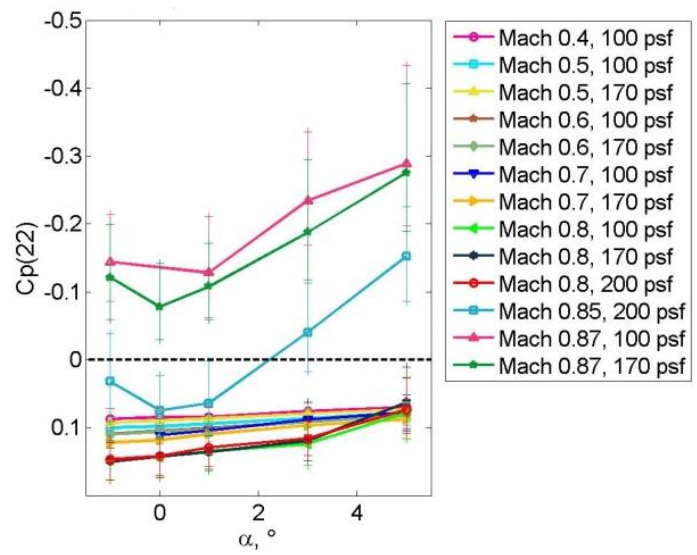

Figure 15. Trailing edge separation assessment, pressure coefficient at the trailing edge

\section{E.Benchmarking test case}

Before leaving the mean pressure distributions from the unforced system data, the smeared time history plot is presented in Figure 16 for the recommended benchmarking testcase at Mach 0.7, $\alpha=3^{\circ}$. This test case contains an oscillatory shock near $10 \%$ chord, but is not thought to contain separated flow regions.

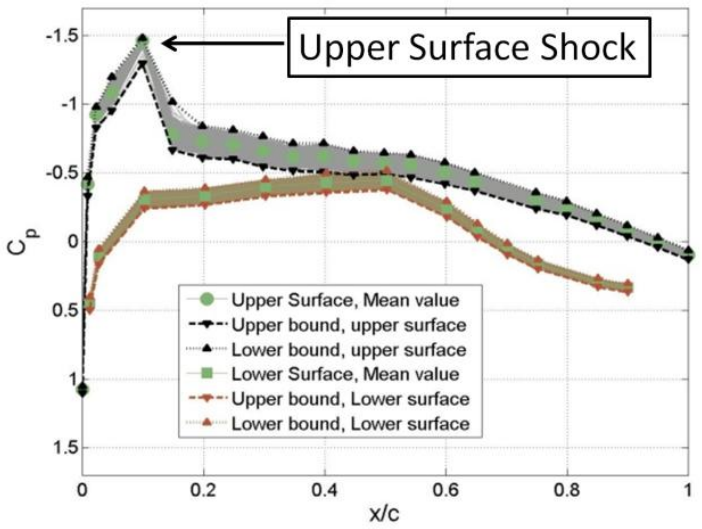

Figure 16. Mach $0.70,3^{\circ} \alpha, 170 \mathrm{psf}$, unforced system data

\section{F. Frequency domain analysis of unforced system data}

The purpose in performing frequency domain analysis of the unforced system data is to determine modes associated with the aerodynamics, specifically the shock oscillation frequency and possibly frequencies associated with alternating attached and separating flow. Identifying the frequency characteristics of the flow field is important for performing higher order aerodynamic unsteady computations. Understanding the time scales for the important flow features provides guidelines for establishing the time step size for those computations, as well as the requirements for the computational time record length.

The results from frequency domain analysis are not conclusive. Numerous modes that are found in the aerodynamic data have been identified as corresponding to structural dynamic modes of the model and splitter plate as well as the wind tunnel blade passage frequency. After eliminating these modes from consideration, the results to date only present a vague picture of possible aerodynamic modes.

Fourier analyses were conducted using the data where only the natural turbulence of the wind tunnel was used to excite the model. The airfoil is divided into three regions of behavior on the upper surface: ahead of the shock, near the shock and aft of the shock. An example power spectral density (PSD) function is shown for a sensor in each of these regions of the airfoil in Figure 17. 


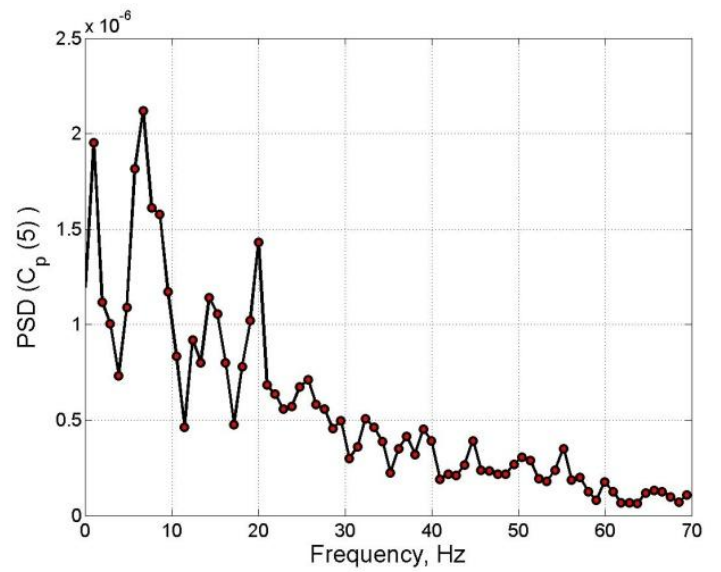

a) Transducer $5, x / c=0.1$, ahead of the shock

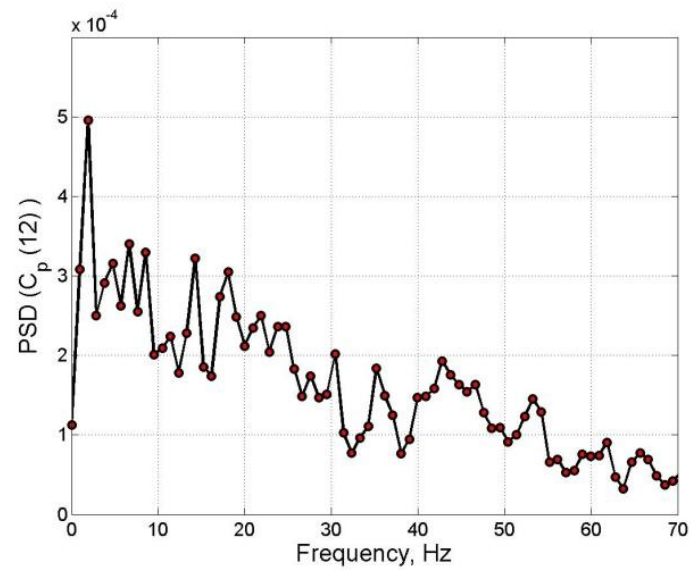

b) Transducer 12, $\mathrm{x} / \mathrm{c}=\mathbf{0 . 4 5}$, at the shock

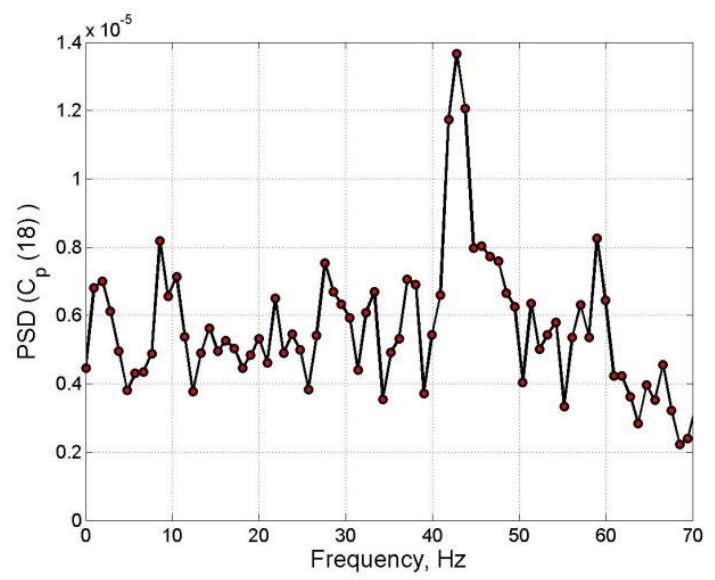

c) Transducer 18, $\mathrm{x} / \mathrm{c}=\mathbf{0 . 8}$, aft of the shock

Figure 17. Power spectra density functions of pressure transducers, Upper surface, Mach $0.85, \alpha 5^{\circ}, 200 \mathrm{psf}$

The transducer ahead of the shock, Figure 17a, picks up the wing first bending mode at $20 \mathrm{~Hz}$, the splitter plate vertical mode at $14.3 \mathrm{~Hz}$ and another mode at near $6.7 \mathrm{~Hz}$. The PSD of the transducer crossed by the shock, Figure $17 \mathrm{~b}$, offers little in terms of frequency peaks. The transducer aft of the shock, Figure 17c, is dominated by an unidentified mode near $42 \mathrm{~Hz}$. Other unidentified modes appear in the aft transducer response near 8 and $58 \mathrm{~Hz}$. The in-plane bending mode is also noticeable in the response at $27 \mathrm{~Hz}$. As mentioned previously, the plots shown are typical for the different regions of the airfoil. The $42 \mathrm{~Hz}$ mode appears for upper surface transducers \#16-22, between $65 \%$ chord and the wing trailing edge. A mode between 6 and $8 \mathrm{~Hz}$ appears for all transducers that are not near the shock. The $58 \mathrm{~Hz}$ mode appears sporadically for different transducers.

PSDs for the lower surface transducers are not presented here. Briefly, for transducers aft of the lower surface shock, the PSDs are dominated by a mode near $8 \mathrm{~Hz}$. The other characteristic of note is that the sensor just aft of the lower surface shock has a dominant mode at $22 \mathrm{~Hz}$, perhaps the wing first bending mode. With regard to the unidentified mode found on the upper surface at $42 \mathrm{~Hz}$ - this frequency appears only moderately in lower surface sensors between the shock and the second to last trailing edge sensor.

There are at least two modes that are seemingly present at the AePW analysis condition that have not been assigned a physical source: $8 \mathrm{~Hz}$ and $42 \mathrm{~Hz}$. The $42 \mathrm{~Hz}$ mode appears in the cusp region $(\mathrm{x} / \mathrm{c}=0.60-1.0)$ on the lower surface and on the upper surface points sufficiently aft of the shock, starting at $\mathrm{x} / \mathrm{c}=0.65$ and extending to the trailing edge. Past work has suggested that the reduced frequency associated with the separated flow phenomena should have a constant reduced frequency. The reduced frequency associated with the $42 \mathrm{~Hz}$ mode at this test condition is 0.38 , using the definition provided earlier. While this reduced frequency seems reasonable in comparison with those observed in the references, this investigation is on-going. 


\section{Forced oscillation data}

The second type of data obtained for the OTT test of the BSCW was forced oscillation data. The data sets shown here contain information generated by oscillating the model about its pitch axis at a single set frequency for the entire time record. Each excitation can be viewed as an angle of attack excursion about the mean angle. That is, for a $5^{\circ}$ case, with an excitation of amplitude $1^{\circ}$, the wing oscillates between $4^{\circ}$ and $6^{\circ}$. Frequency response functions calculated from the forced oscillation data were considered to be the principal comparison data for the AePW. Examination of these data sets shows that the unforced system dynamic characteristics and the forced system responses are closely linked.

The forced oscillation data is examined using similar representations of the pressure coefficients: time histories, smear plots showing the time history data as a function of chord location, statistics, limits and histograms. Additionally, Fourier analysis is performed producing frequency response functions (FRFs) to examine the pressure response relative to the measured angle of attack.

\section{A.Time history representation}

One of the AePW computational test cases was the $10 \mathrm{~Hz}$ forced oscillation case, with excitation amplitude of $1^{\circ}$. This case will be used here to illustrate the data characteristics. Time histories of the upper and lower surface pressure coefficients are shown in Figure 18. The forcing frequency can be observed in each of the sensor traces shown. On the upper surface, the sensors that the shock moves across again have a more ragged character than the other sensors. This will be discussed in more detail shortly. The clean sinusoidal traces shown in Figure 18b correspond to lower surface sensors located ahead of the lower surface shock and/or ahead of the lower surface cusp. The sensors located in the cusp region show the sinusoidal character in general, but appear to have random noise superimposed on the data traces.

It is interesting to notice the different relative time shifts among the pressure time histories. These time shifts are more formally characterized by the phase angles in the frequency response function analysis to be discussed.

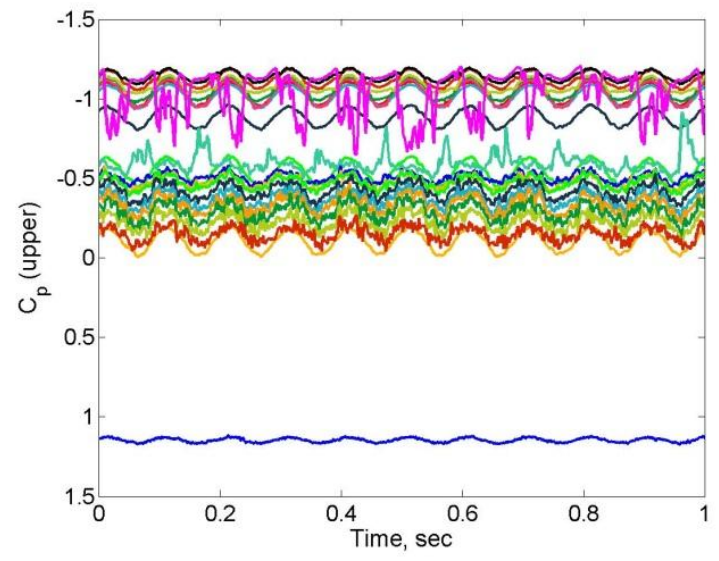

a) Upper surface

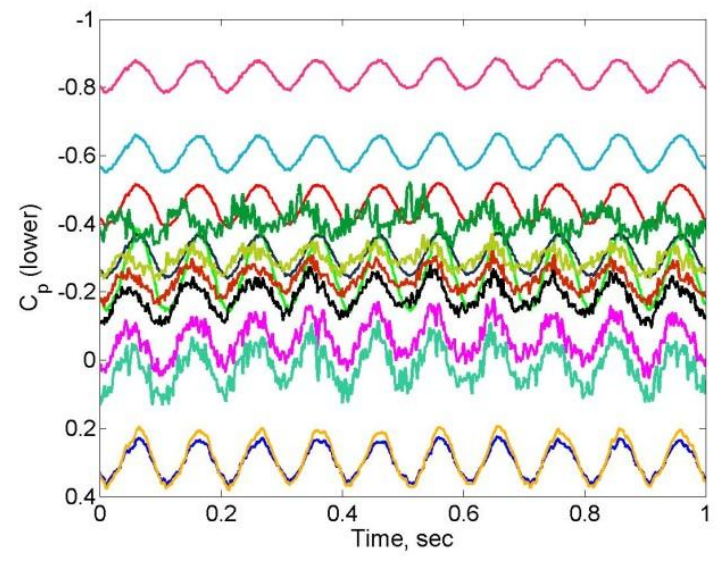

b) Lower surface

Figure 18. Time histories of pressure coefficients, Mach $0.85,5^{\circ} \alpha, 200 \mathrm{psf}, 10 \mathrm{~Hz}$ forced oscillation

The sensors in the region of the upper surface shock are examined in more detail in Figure 19. The behavior here is similar to that observed for the unforced system, but the response is more dramatic. Similar to the unforced system case, the sensors of greatest interest for this test condition are transducers 12 and 13, located near the midchord.

Examining the behavior of the pressure coefficient at transducer 12, there are two different types of behavior exhibited. Some portions of the time history show low level responses which appear to be $1 / 2$ sinusoids that hit a floor value and are out of phase with the angle of attack command. The low level responses occur when the airfoil is pitching nose downward. As the nose pitches downward, the pressure coefficient increases, showing reduced lift. 
These portions correspond to the shock being aft of this pressure transducer during these segments of time. The second behavior is a higher level response that is approximately in phase with the angle of attack in terms of the sinusoidal portion, but seemingly has a random component also. This occurs as the nose pitches upward.

At this test condition, as the airfoil pitches nose upward, increasing the angle of attack, the upper surface shock moves forward. As it pitches nose downward, decreasing the angle of attack, the upper surface shock moves aft. This dynamic behavior agrees with the characteristics observed by examining the unforced data for this Mach number, Mach 0.85 .

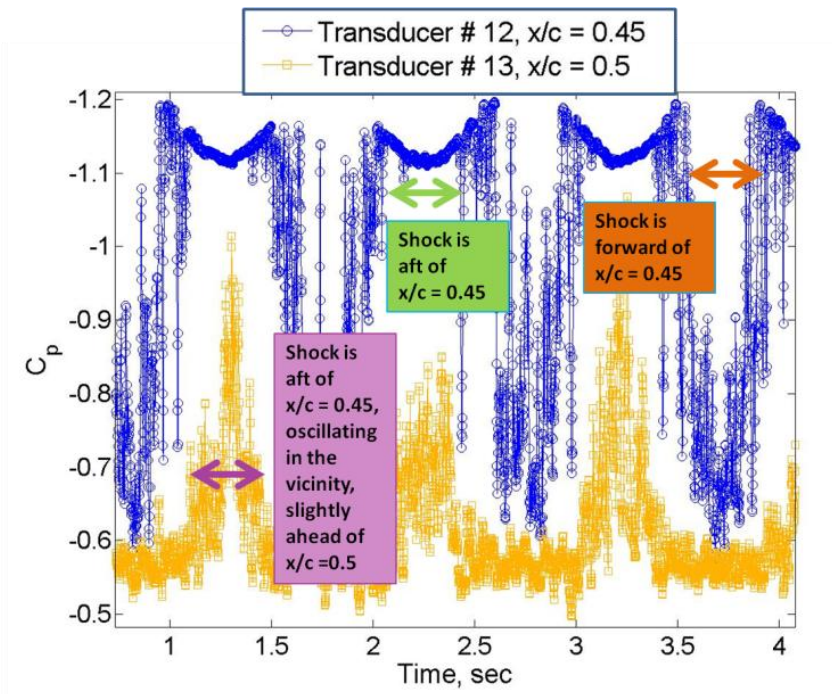

Figure 19. Time history of pressure coefficients in the vicinity of the oscillating shock, $10 \mathrm{~Hz}$ excitation frequency, close up view

A smeared time history plot showing both the upper and lower surfaces is presented in Figure 20. The forced oscillation data is shown overplotted with the unforced system data. For all sensors, the unforced system data lies within the bounds of the forced system response. The plot shows that the largest influence of the forcing oscillation is near the upper surface shock and near a knee in the lower surface distribution near $\mathrm{x} / \mathrm{c}=0.15$. The smallest change introduced is just ahead of the cusp region on the lower surface. This suggests that the flow field there is relatively insensitive to angle of attack changes at this test condition, even changes applied dynamically. Similar insensitivity in the cusp region was observed using smear plots at different excitation frequencies.

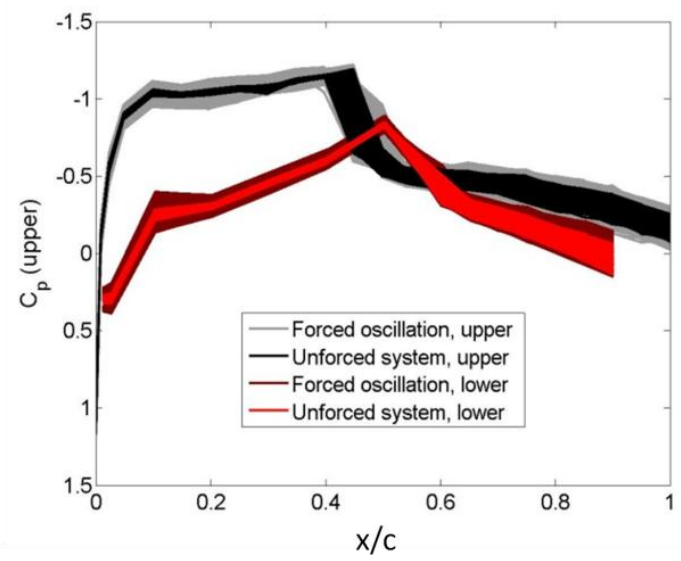

Figure 20. Smeared time history plot vs. chord location for forced oscillation at $10 \mathrm{~Hz}$, AePW test condition (Mach $\left.0.85,5^{\circ} \alpha\right)$

Figure 21 shows the pressure data obtained at 3 chord locations on the wing upper surface. A portion of the time histories and histograms are presented for the 3 selected chord locations. Ahead of the shock the pressure 
response is very sinusoidal, with only small cropping obvious at the extremes of the sine function. The resulting histogram qualitatively resembles an arcsine distribution, which is the expected distribution for a sinusoid. Figure $21 \mathrm{~b}$ shows the characteristics of behavior for a sensor when a shock oscillates across it. The associated histogram is highly skewed towards the low end. This skewness reflects the floor-hitting behavior observed in the time history. Again, remember that the vertical axis is inverted, so a floor looks like a ceiling. The left skewness indicates that the shock is principally located aft of this sensor, as discussed earlier for the unforced system results. Right skewness would indicate that the shock is principally located forward of this sensor, a characteristic that was observed by examining the histogram for transducer 13, at the next aft chord location. Figure 21c shows the characteristics of a sensor in the separated flow that exists at this test condition aft of the upper surface shock. While the time history contains the forced oscillation sinusoid, there is an additional random-looking component superimposed. The resulting histogram qualitatively resembles a combination of Gaussian and arcsine distributions.
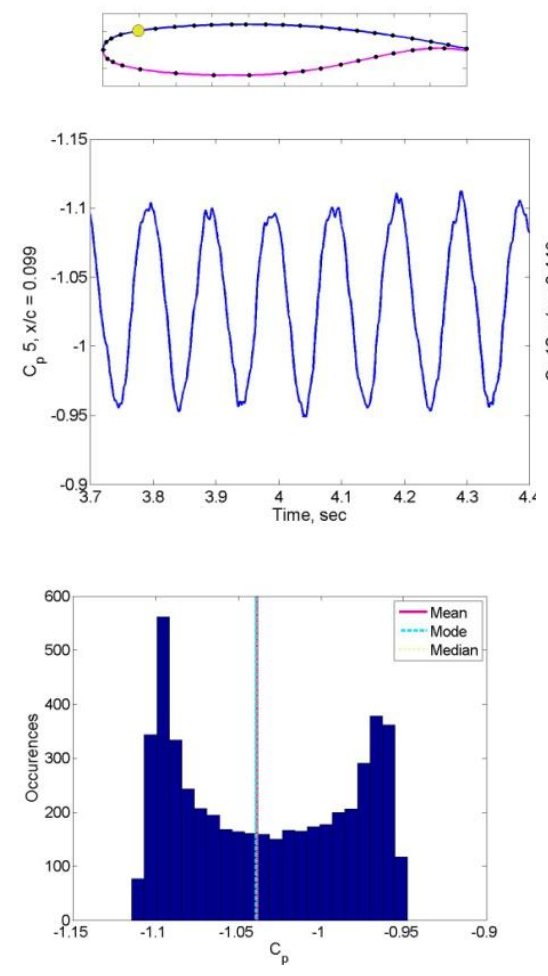

a) Pressure Transducer 5, $\mathbf{x} / \mathbf{c}=\mathbf{0 . 1}$, in region of attached turbulent flow
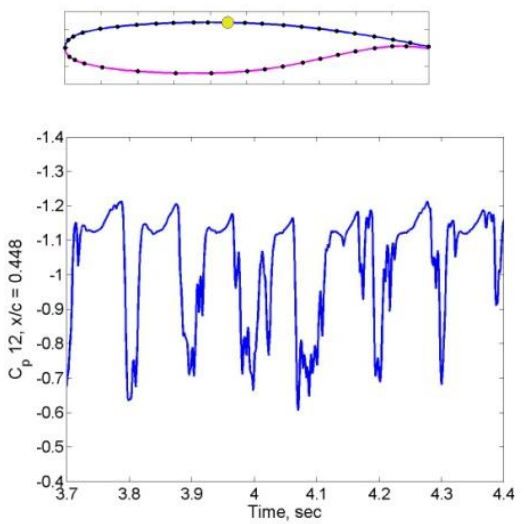

i) time history plots

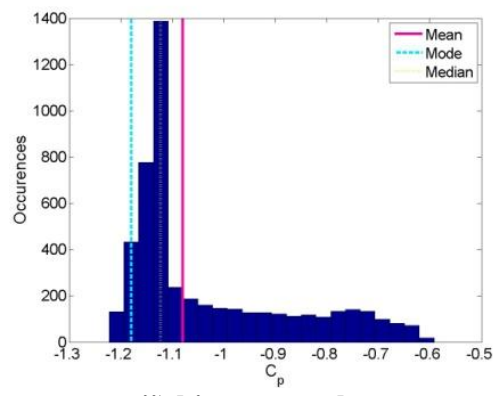

ii) histogram plots

b) Pressure transducer 12, $\mathrm{x} / \mathrm{c}=\mathbf{0 . 4 5}$, in region of shock oscillation
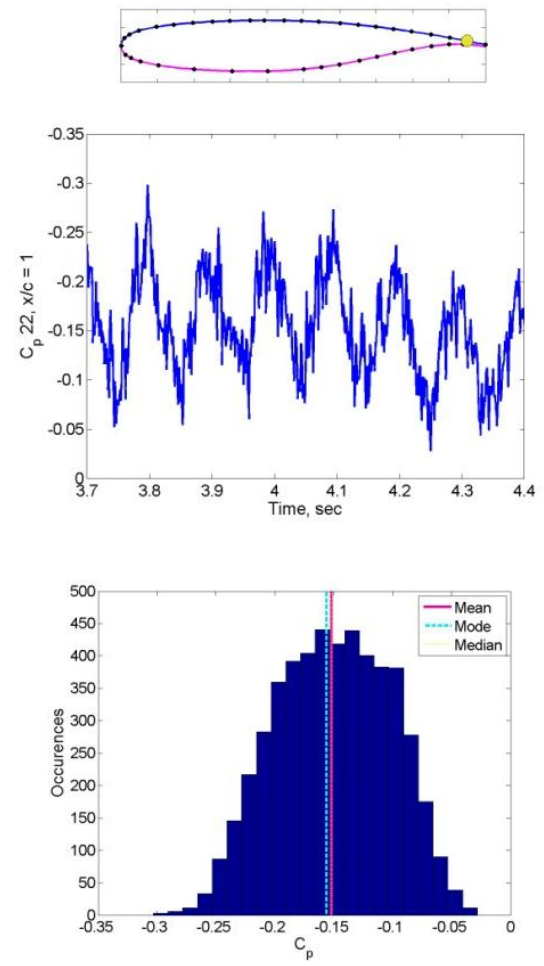

c) Pressure transducer 22, $\mathbf{x} / \mathbf{c}=\mathbf{1 . 0}$, in separated flow region at trailing edge

Figure 21. Pressure coefficient behavior in different regions of the airfoil, AePW analysis condition (Mach 0.85, $\alpha 5^{\circ}, 200 \mathrm{psf}$ ), $10 \mathrm{~Hz}$ forced oscillation

\section{B. Frequency domain analysis}

The Fourier analysis parameters were tuned for each data set of forced excitation data. The tuning was based on achieving the maximum coherence between the pressure responses and the angle of attack which was used as the reference sensor in computing frequency response functions. Only the coherence at the excitation frequency was considered in each case. A brief convergence study determined that 12 overlap averaged segments produced a converged answer. For each forced excitation data set, a different Fourier block size was used, however, the same block size was used for all sensors within a given data set. Hanning windowing and data segment overlap of $67 \%$ were employed in the final analyses. 
Details of the coherence are discussed for the AePW excitation cases and at $30 \mathrm{~Hz}$. For the $1 \mathrm{~Hz}$ case, all upper surface sensors have coherences above 0.992. In this instance, the lower surface coherence functions determined the tuned block size. A significant reduction in the coherence function was observed for the sensors in the cusp region, particularly at $x / c=0.752$, which is near the steepest geometric change. The general decrease in coherence for the lower surface responses in the cusp region indicates that the pressure response in this region is not as driven by the oscillatory angle of attack as the other sensors. For the $10 \mathrm{~Hz}$ case, the upper surface transducer at the foot of the shock is the sensor that produces the worst coherence value. This sensor was the determining sensor in choosing the block size for this test case. For the $30 \mathrm{~Hz}$ case, all upper surface pressures aft of the wake have coherence functions that are significantly affected by the choice of the Fourier block size. Again, the transducer located at the foot of the shock has the worst coherence. Combining the peak coherence value from the other sensors with the trends of this sensor resulted in selecting a Fourier block size that was not optimal for any particular sensor, but was subjectively viewed as the compromise best choice.

Frequency response functions estimates at the excitation frequencies were previously published for a subset of the excitation frequencies. The responses were shown to not be monotonic functions with regard to frequency. Presenting the results for all of the excitation frequencies lends physical insight into the underlying cause. Figure 22 and Figure 23 show surface plot of the magnitude and phase as functions of wing chord and excitation frequency for the upper and lower surface pressures. The colors emphasize the values shown on the vertical axis in each subplot. The obvious characteristics are the mid-chord shock and the vertical splitter plate mode near $14 \mathrm{~Hz}$. The shock dynamics dominate the response for all excitation frequencies. The magnitude of the response is observed to decline monotonically with increasing frequency until the splitter plate mode interferes. The information at $20 \mathrm{~Hz}$ and 30 $\mathrm{Hz}$ should not be interpreted as necessarily corresponding to an increase in response, because the excitation magnitudes for these cases are substantially reduced relative to the other excitations.

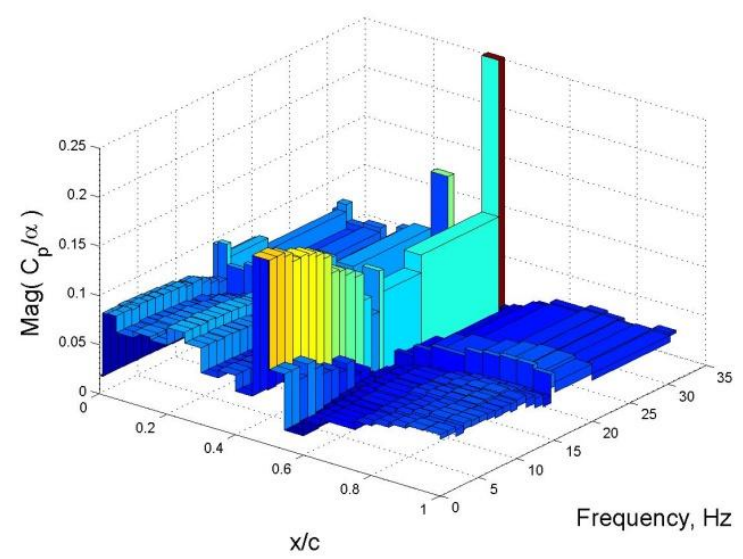

a) Upper surface FRF Magnitude

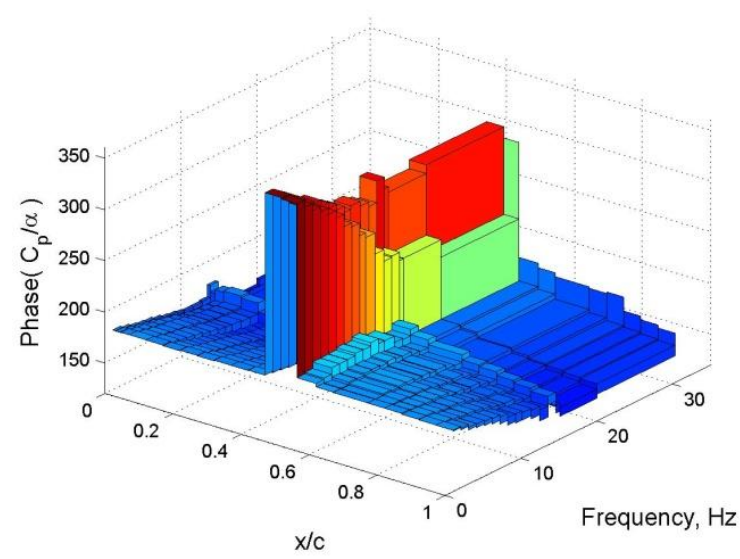

b) Upper surface FRF Phase, degs

Figure 22. Frequency response functions for the upper surface pressure coefficients, relative to angle of attack, Magnitude is in units of $1 / \mathrm{deg}$ 


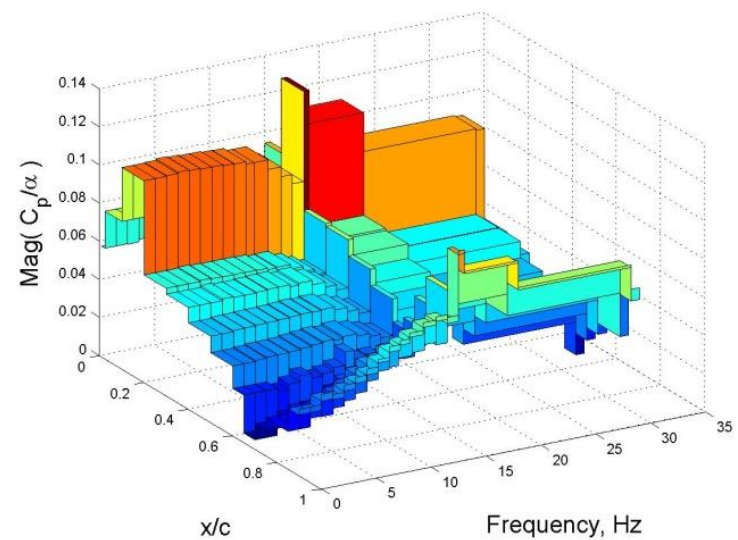

a) Lower surface FRF Magnitude

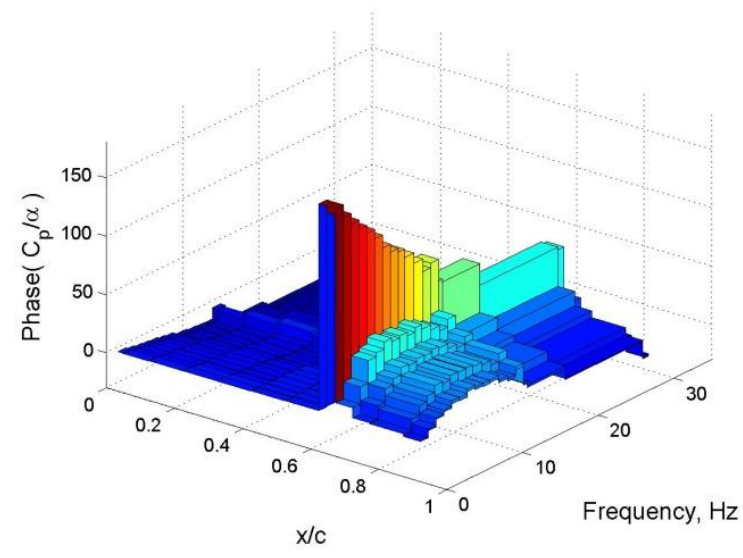

b) Lower surface FRF Phase, degs

Figure 23. Frequency response functions for the lower surface pressure coefficients, relative to angle of attack, Magnitude is in units of $1 / \mathrm{deg}$

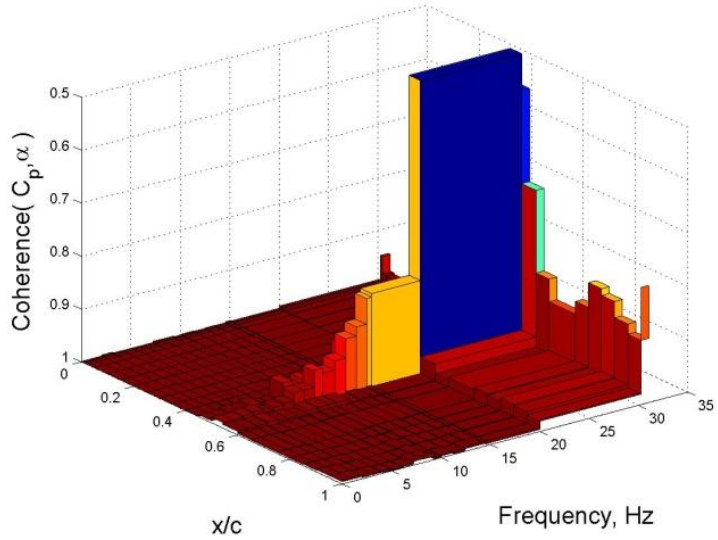

a) Upper surface coherence

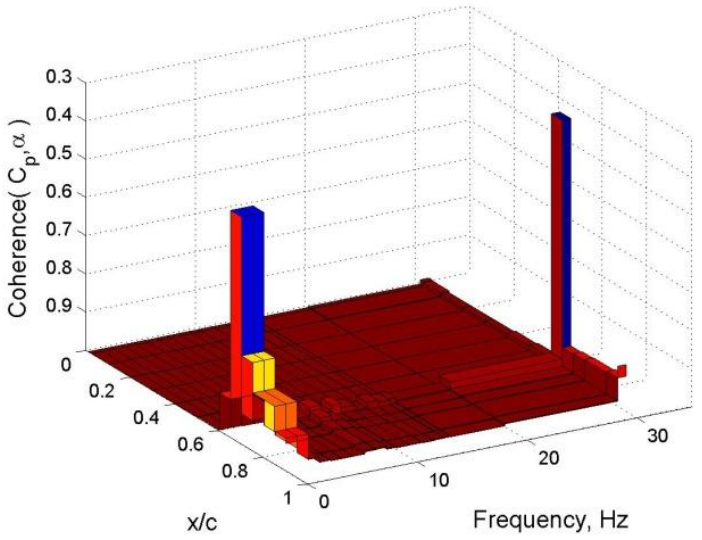

b) Lower surface coherence

Figure 24. Coherence functions for the pressure coefficients, relative to angle of attack; vertical axis inverted

A natural question that arises is why the forced excitation data should not be used to determine the frequencies associated with aerodynamic modes, rather than the unforced system data. An example PSD of the forced system response is shown in Figure 25. This data corresponds to a sensor located well away from the shock, at the quarter chord. This case is for a $10 \mathrm{~Hz}$ excitation. From the response, it is clear that superharmonics (multiples) of the forcing frequency are contaminating the system response. The source of these superharmonics appears to lie within the controller for the OTT, rather than in the aerodynamics.

This phenomenon is present in all of the forced excitation data examined to date, including the frequency sweep data, where entire blocks of frequency are aliased to higher frequency blocks. This characteristic has rendered interpretation of the forced excitation data difficult at non-excitation frequencies. For this reason, the forced system data is examined only at the forcing frequency. Because of this phenomenon, resolving aerodynamic-originating phenomena has been limited, to date, to consideration of unforced system data sets. 


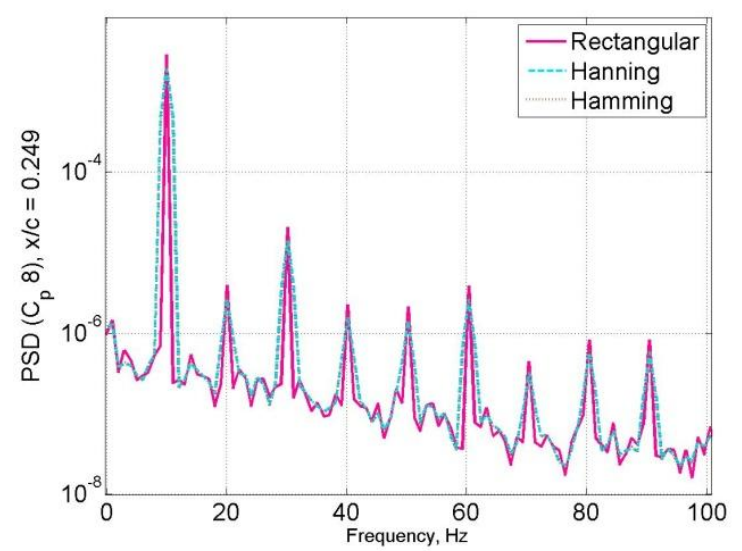

Figure 25. Aliasing of excitation frequency and influence of windowing, $10 \mathrm{~Hz}$ excitation, nfft 994, $67 \%$ overlap

\section{Benchmarking test case}

Time history and histogram data is shown for the $10 \mathrm{~Hz}$ forced oscillation case for the recommended benchmarking test case, Figure 26. The time history shown at Mach 0.7 for the forward pressure transducer shows the shock oscillation in response to a forced pitch oscillation at $10 \mathrm{~Hz}$. The data indicates that the flow is not likely to be separated, neither at the foot of the shock nor at the trailing edge. These details will be presented in the next section of the paper. The presence of the oscillating shock, without the complications of separated flow makes this a good entry-level test case for computational benchmarking.
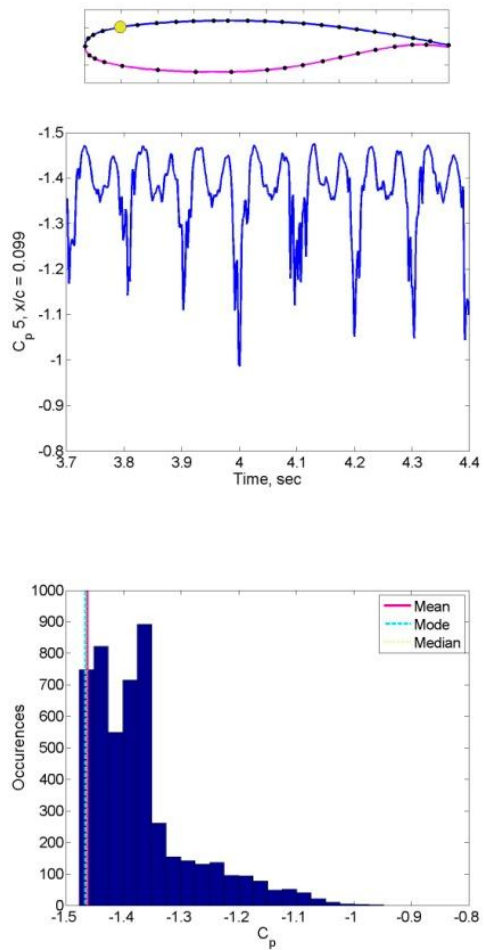

a) Pressure Transducer 5, $\mathrm{x} / \mathrm{c}=\mathbf{0 . 1}$, in region of shock oscillation
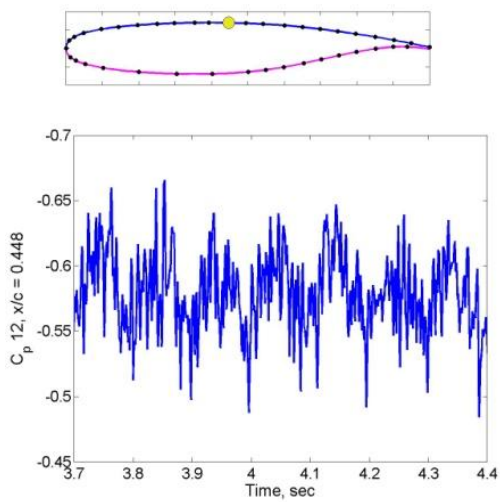

i) time history plots

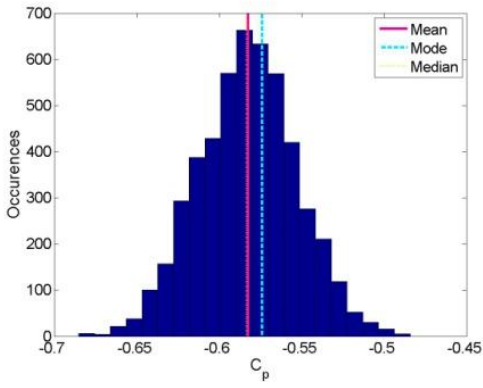

ii) histogram plots

b) Pressure transducer 12, $\mathrm{x} / \mathrm{c}=\mathbf{0 . 4 5}$, aft of shock
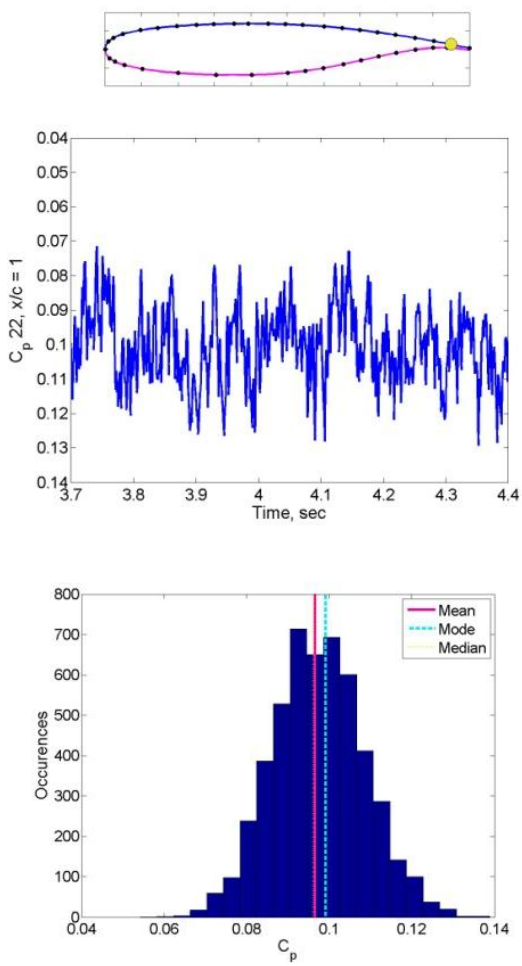

c) Pressure transducer 22, $\mathrm{x} / \mathrm{c}=\mathbf{1 . 0}$, aft of shock, near trailing edge

Figure 26. Pressure coefficient behavior in different regions of the airfoil, Suggested benchmarking analysis condition (Mach $0.70, \alpha 3^{\circ}, 170 \mathrm{psf}$ ), $10 \mathrm{~Hz}$ forced oscillation 


\section{D.Amplitude effects}

The characteristics of the BSCW at the AePW test condition are nonlinear functions of amplitude. Only data sets at 4 and $5 \mathrm{~Hz}$ are available for direct comparison between two excitation magnitudes. Data sets with 1 degree and 2 degree amplitude at $4 \mathrm{~Hz}$ are examined.

The time histories of pressure responses from the two excitation amplitudes are qualitatively different. The pressure measurement of transducer $12, \mathrm{x} / \mathrm{c}=0.5$, captures the pressure changes as the shock movement forward and aft with each forced oscillation cycle. Figure 27 shows the angle of attack overplotted with the pressure coefficients for the two cases. All of the data has been detrended (i.e. the mean value removed from the data) and the angle of attack normalized for plotting purposes. The low angle of attack portion of each cycle corresponds to the inverted half sinusoid portions of the pressure coefficient distributions. These portions of the time history show the higher values of pressure coefficient magnitude correspond to those portions of the cycle where the shock has moved aft and this sensor is in the supersonic plateau region ahead of the shock. The inverted half sinusoid shape of this portion of the pressure coefficient shows that as the shock continues to move aft with decreasing angle of attack; this transducer is further forward of the peak pressure coefficient magnitude that occurs at the shock leading edge. As the wing pitches back upward from its minimum nose-down value, the pressure coefficient then rises again as the shock moves forward.

When the shock moves forward past this transducer the dramatic drop in the pressure coefficient magnitude occurs. This occurs for nose-up angles of attack at this test condition. Note that the true excursion for the angle of attack is between approximately $4^{\circ}$ and $6^{\circ}$ for the low amplitude case and between $3^{\circ}$ and $7^{\circ}$ for the large amplitude case. The dramatic drop in magnitude that is aft of the shock is seen for both amplitude cases. For the larger amplitude case, the pattern is qualitatively simpler than for the low amplitude case. Once the shock moves forward of this transducer, the high amplitude case shows the pressure coefficient continues to decline in magnitude until its dramatic jump as the shock moves back aft of this sensor. Midway through this half cycle, the angle of attack has reached its maximum, nose-up, value.

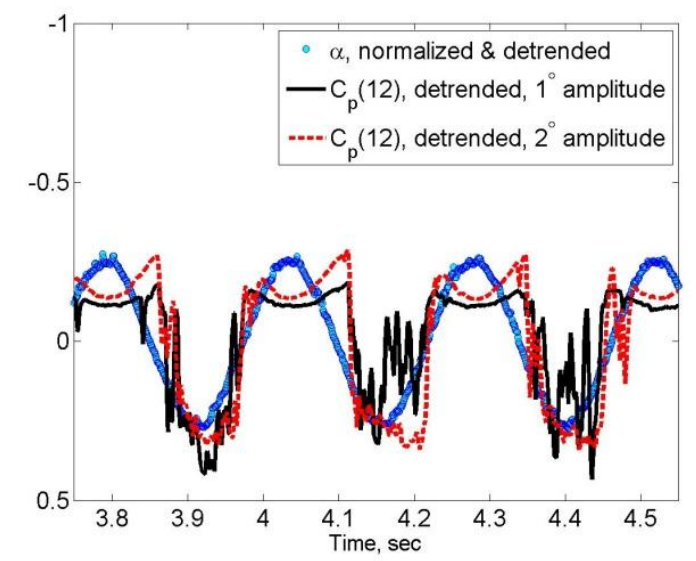

Figure 27. Effect of excitation amplitude at AePW test condition, Mach $\mathbf{0 . 8 5}, \alpha=5^{\circ}$

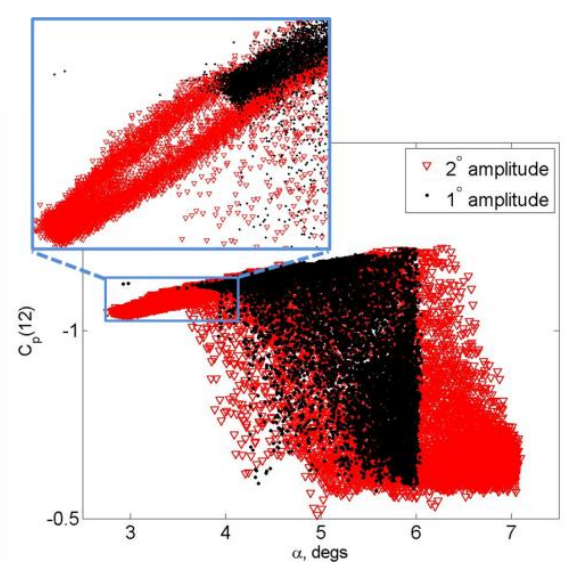

Figure 28. Pressure coefficient versus angle of attack 


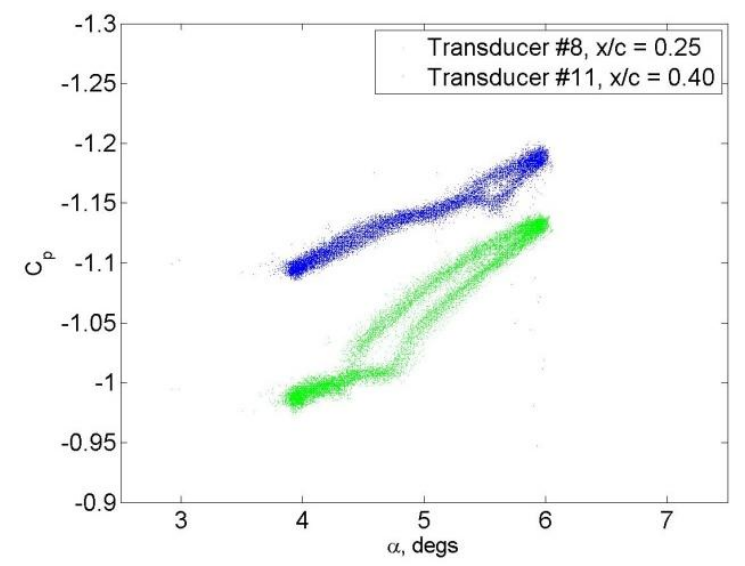

Figure 29. $4 \mathrm{~Hz}$, amplitude 1 degree, AePW test condition

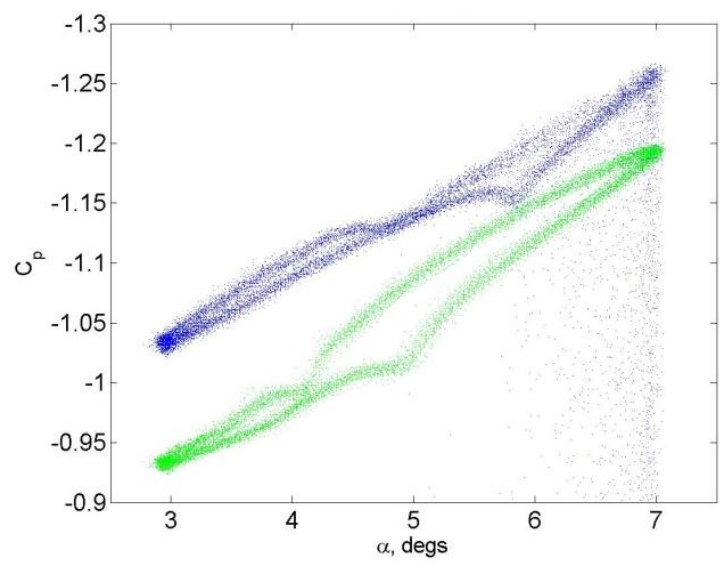

Figure 30. $4 \mathrm{~Hz}$, amplitude 2 degs, AePW test condition

The higher amplitude produces a hysteresis loop, Figure 28, showing that the flow behaves differently at the same angle of attack, depending on whether or not the angle of attack is increasing or decreasing. An elliptical hysteresis loop would indicate a pure time delay between the angle of attack change and the movement of the shock. The shape of the hysteresis loop observed here, however, are not elliptical, but have flat spots and in some cases intersecting loops. The hysteresis is present in all sensors between $\mathrm{x} / \mathrm{c}=0.1$ and 0.5 (transducers 5-12) for this test condition. The shapes of the hysteresis loops are more clearly seen in Figure 29 and Figure 30, which show response from transducers 8 and 11, plotted separately for the two excitation amplitudes.

The nonlinear amplitude dependence suggests that linear data analysis methods, such as Fourier domain methods, are likely insufficient for analyzing the BSCW data set.

\section{Concluding remarks}

The BSCW was a challenging test case for the AePW analysts. The challenges of this test case can be traced to the flow physics acting on this supercritical airfoil at the AePW test condition. These challenges include an oscillatory shock, present even in the unforced system "steady" data. The oscillatory shock is likely forced by separated flow over the aft portion of the upper surface, at both the foot of the shock and at the wing trailing edge. The oscillatory cases may contain alternating attached and separated flow, particularly for those conditions identified as separation onset conditions. Because the BSCW contains significant influences of separated flow, future analysts should likely consider applying methods that are suited to accurately capturing the dynamics of separated flow. On-going efforts are focused on hybrid large eddy simulation (LES) methods.

A second test case to use as a benchmarking case prior to attempting the challenging AePW test case is presented in this paper also. At Mach 0.7, $3^{\circ}$ angle of attack, the experimental data indicates that although there is a shock present on the upper surface, the flow is not separated.

The presence of shock motion and other dynamics in a presumed static data set can have the following effects on the resulting mean pressure distribution: smearing the shock over several chord stations, reducing the magnitude of the shock and canting the shock towards the leading edge. A mean value is only appropriate to represent the time history data set if that time history has a symmetric histogram. The use of the mean value should not be relied on to represent a data set, particularly where a shock is present. Minimally, other statistics of the data set, such as the mode, standard deviation, skewness, kurtosis, maximum and minimum values are recommended. Not obtaining or retaining the time-dependent data severely limits the ability to interpret dynamic characteristics of the system.

Amplitude-dependent properties have been demonstrated to exist for the BSCW. The nonlinearities examined to data suggest that data analysis techniques other than Fourier analysis are required to properly characterize this system. While this paper has focused on analysis of the experimental data set, more advanced computational solutions that properly capture these flow features will also require rethinking the data processing techniques. 


\section{Acknowledgments}

The authors thank the BSCW computational teams who contributed to the AePW effort and continue to study this seemingly easy problem. The insights from their analyses have driven and focused analysis of this experimental data set. The authors also thank the NASA Fixed Wing project and the NASA Engineering and Safety Center for their financial sponsorship of this data analysis.

\section{References}

1 "https://c3.nasa.gov/dashlink/projects/47/", January 2013.

${ }^{2}$ Heeg, J.; et al, "Plans for an Aeroelastic Prediction Workshop," IFASD-2011-110, International Forum on Aeroelasticity \& Structural Dynamics, June 2011, Paris.

${ }^{3}$ Heeg, J., Chwalowski, P., Florance, J.P., Wieseman, C.D., Schuster, D.M., and Perry, B. III, "Overview of the Aeroelastic Prediction Workshop," AIAA 2013-0783, 51 ${ }^{\text {st }}$ AIAA Aerospace Sciences Meeting, January 7-10, 2013, Grapevine, Texas.

${ }^{4}$ Schuster, D.M., Heeg, J., Wieseman, C.D., and Chwalowski, P., "Analysis of test case computations and experiments for the Aeroelastic Prediction Workshop," AIAA-2013-0788, 51 ${ }^{\text {st }}$ AIAA Aerospace Sciences Meeting, January 7-10, 2013, Grapevine, Texas.

${ }^{5}$ Mavriplis, D.J., Yang, Z., and Long, M., and Sitaraman, J., "Results using NSU3D for the First Aeroelastic Prediction Workshop," AIAA 2013-0786, 51 ${ }^{\text {st }}$ AIAA Aerospace Sciences Meeting, January 7-10, 2013, Grapevine, Texas.

${ }^{6}$ Raveh, D.E., Yossef, Y.M. and Levy, Y, “Flow simulations for the first Aeroelastic Prediction Workshop using the EZNSS code," AIAA 2013-0787, , 51 ${ }^{\text {st }}$ AIAA Aerospace Sciences Meeting, January 7-10, 2013, Grapevine, Texas.

7 Chwalowski, P., Heeg, J., Wieseman, C.D., and Florance, J.P., "FUN3D analyses in support of the First Aeroelastic Prediction Workshop," AIAA 2013-0785, , $51^{\text {st }}$ AIAA Aerospace Sciences Meeting, January 7-10, 2013, Grapevine, Texas.

${ }^{8}$ Piatak, David J. and Cleckner, Craig S. Oscillating Turntable for the Measurement of Unsteady Aerodynamic Phenomenon, Journal of Aircraft, Vol 14, No. 1, Jan. -Feb. 2003.

${ }^{9}$ Mabey, D.G., "Buffeting criteria for a systematic series of wings," Journal of Aircraft, Vol 26, No 6, June 1989.

${ }^{10}$ Pearcey, H.H., "Somoe effects of shock-induced separation of turbulent boundary layers in transonic flow past aerofoils," Aeronautical Research Council Reports \& Memoranda No 3108, June, 1955.

${ }^{11}$ Hurley, F.X., Spaid, F.W., Roos, F.W., Stivers, L.S., Jr., and Bandettini, A., "Detailed transonic flow field measurements about a supercritical airfoil section," NASA TM X-3244, July 1975.

${ }^{12}$ Bartels, R.E. and Edwards, J.W., "Cryogenic tunnel pressure measurements on a supercritical airfoil for several shock buffet conditions," NASA TM 110272, Sept 1997.

${ }^{13}$ Cunningham, Atlee, M., Jr, and Spragle, Gregory S., "A study of the effects of Reynolds number and Mach number on constant pressure coefficient jump for shock-induced trailing-edge separation," NASA Contractor Report 4090, contract NASI17955, August 1987.

${ }^{14}$ McDevitt, John B., and Okuno, Arthur F., "Static and dynamic pressure measurements on a NACA 0012 airfoiil in the Ames high Reynolds number facility," NASA TP-2485, June 1985.

${ }^{15}$ Charpin, F., "Buffeting tests," NASA Technical translation TT F-12,776, extract from La Recherche Aerospatiale, Tp 664, p 9-16, 1968.

${ }^{16}$ Reed, Wilmer, H., "Aeroelasticity matters: Some reflections on two decades of testing in the NASA Langley Transonic Dynamics Tunnel," NASA TM-83210, 1981.

${ }^{17}$ Dansberry, Bryan E., Durham, Michael H., Bennett, Robert M., Turnock, David L, Silva, Walter A, and Rivera, Jose A, Jr. "Physical properties of the Benchmark models program supercritical wing," NASA TM-4457, 1993.

${ }_{18}$ Bennett, R.M.; Eckstrom, C.E.; Rivera, J.A., Jr.; Dansberry, B.E.; Farmer, M.G.; and Durham, M.H.: "The Benchmark Aeroelastic Models Program- Description and Highlights of Initial Results," NASA TM 104180, December 1991.

${ }^{19}$ Dansberry, B.E.; Durham, M.H.; Bennett, R.M.; Rivera, J.A.; Silva, W.A.; and Wieseman, C.D.; Experimental Unsteady Pressures at Flutter on the Supercritical Wing Benchmark Model." AIAA-93-1592-CP, April 1993.

${ }^{20}$ Kvaternik, R.G., "Computer programs for calculating the isentropic flow properties for mixtures of R-134a and air," NASA TM-2000-210622, Nov. 2000.

${ }^{21}$ Schuster, David M., "Aerodynamic measurements on a large splitter plate for the NASA Langley Transonic Dynamics Tunnel,” NASA TM-2001-210828, March 2001.

${ }^{22}$ Heeg, J., Chwalowski, P., Wieseman, C.D., Florance, J.P., and Schuster, D.M., "Lessons learned in the selection and development of test cases for the Aeroelastic Prediction Workshop: Rectangular Supercritical Wing," AIAA-2013-0784, 51 ${ }^{\text {st }}$ AIAA Aerospace Sciences Meeting, January 7-10, 2013, Grapevine, Texas.

${ }^{23}$ Harris, C., "NASA supercritical airoils: a matrix of family-related airfoils," NASA TP 2969, 1990.

${ }^{24}$ Harris, C., "Aerodynamic characteristics of a 14-percent-thick NASA supercritical airfoil designed for a normal-force coefficient of 0.7," NASA TM X-72712, 1975. 